\title{
Combined effect of the entomopathogenic fungus Metarhizium robertsii and avermectins on the survival and immune response of Aedes aegypti larvae
}

\author{
Yuriy A Noskov ${ }^{\text {Corresp. }, ~}{ }^{1,2}{ }$, Olga V Polenogova ${ }^{1}$, Olga N Yaroslavtseva ${ }^{1}$, Olga E Belevich ${ }^{1}$, Yuriy A Yurchenko ${ }^{1}$, \\ Ekaterina A Chertkova ${ }^{1}$, Natalya A Kryukova ${ }^{1}$, Vadim Y Kryukov ${ }^{1}$, Viktor V Glupov ${ }^{1}$ \\ ${ }^{1}$ Institute of Systematics and Ecology of Animals, Siberian Branch of Russian Academy of Sciences, Novosibirsk, Russia \\ 2 Tomsk State University, Tomsk, Russia \\ Corresponding Author: Yuriy A Noskov \\ Email address: yunoskov@gmail.com
}

Combination of insect pathogenic fungi and microbial metabolites is a prospective method for mosquito control. The effect of the entomopathogenic fungus Metarhizium robertsii J.F. Bischoff, S.A. Rehner \& Humber and avermectins on the survival and physiological parameters of Aedes aegypti (Linnaeus, 1762) larvae (dopamine concentration, glutathione S-transferase (GST), nonspecific esterases (EST), acid proteases, lysozymelike, phenoloxidase (PO) activities) was studied. It is shown that the combination of these agents leads to a synergistic effect on mosquito mortality. Colonization of Ae. aegypti larvae by hyphal bodies following water inoculation with conidia is shown for the first time. The larvae affected by fungi are characterized by a decrease in PO and dopamine levels. In the initial stages of toxicosis and / or fungal infection (12 h posttreatment), increases in the activity of insect detoxifying enzymes (GST and EST) and acid proteases are observed after monotreatments, and these increases are suppressed after combined treatment with the fungus and avermectins. Lysozyme-like activity is also most strongly suppressed under combined treatment with the fungus and avermectins in the early stages posttreatment (12 h). Forty-eight hours posttreatment, we observe increases in GST, EST, acid proteases, and lysozyme-like activity under the influence of the fungus and / or avermectins. The larvae affected by avermectins accumulate lower levels of conidia than avermectin-free larvae. On the other hand, a burst of bacterial CFUs is observed under treatment with both the fungus and avermectins. We suggest that disturbance of the responses of the immune and detoxifying systems under the combined treatment and the development of opportunistic bacteria may be among the causes of the synergistic effect. 
1 Combined effect of the entomopathogenic fungus Metarhizium robertsii and avermectins on

2 the survival and immune response of Aedes aegypti larvae

3 Yuriy A. Noskov ${ }^{1,2}$, Olga V. Polenogova ${ }^{1}$, Olga N. Yaroslavtseva ${ }^{1}$, Olga E. Belevich ${ }^{1}$, Yuriy A.

4 Yurchenko $^{1}$, Ekaterina A. Chertkova ${ }^{1}$, Natalya A. Kryukova ${ }^{1}$,Vadim Y. Kryukov ${ }^{1}$, Viktor V.

5 Glupov $^{1}$

$6{ }^{1}$ Institute of Systematics and Ecology of Animals, Siberian Branch of Russian Academy of

7 Sciences, Novosibirsk, Russia

$8 \quad 2$ Tomsk State University, Tomsk, Russia

9 Corresponding author:

10 Yuriy Noskov ${ }^{1,2}$

11 Frunze str., 11, Novosibirsk, 630091, Russia

12 Email address: yunoskov@gmail.com 
14 Abstract

15 Combination of insect pathogenic fungi and microbial metabolites is a prospective method for

16 mosquito control. The effect of the entomopathogenic fungus Metarhizium robertsii J.F.

17 Bischoff, S.A. Rehner \& Humber and avermectins on the survival and physiological parameters

18 of Aedes aegypti (Linnaeus, 1762) larvae (dopamine concentration, glutathione S-transferase

19 (GST), nonspecific esterases (EST), acid proteases, lysozyme-like, phenoloxidase (PO)

20 activities) was studied. It is shown that the combination of these agents leads to a synergistic

21 effect on mosquito mortality. Colonization of Ae. aegypti larvae by hyphal bodies following

22 water inoculation with conidia is shown for the first time. The larvae affected by fungi are

23 characterized by a decrease in PO and dopamine levels. In the initial stages of toxicosis and / or

24 fungal infection ( $12 \mathrm{~h}$ posttreatment), increases in the activity of insect detoxifying enzymes

25 (GST and EST) and acid proteases are observed after monotreatments, and these increases are

26 suppressed after combined treatment with the fungus and avermectins. Lysozyme-like activity is

27 also most strongly suppressed under combined treatment with the fungus and avermectins in the

28 early stages posttreatment (12 h). Forty-eight hours posttreatment, we observe increases in GST,

29 EST, acid proteases, and lysozyme-like activity under the influence of the fungus and / or

30 avermectins. The larvae affected by avermectins accumulate lower levels of conidia than

31 avermectin-free larvae. On the other hand, a burst of bacterial CFUs is observed under treatment

32 with both the fungus and avermectins. We suggest that disturbance of the responses of the

33 immune and detoxifying systems under the combined treatment and the development of

34 opportunistic bacteria may be among the causes of the synergistic effect.

\section{Introduction}

36 Mosquitoes are obligate intermediate hosts for a variety of pathogens that cause human mortality and morbidity worldwide. Aedes aegypti is considered to be an important vector of human diseases such as dengue and yellow fever, chikungunya, and Zika infections (Tolle, 2009; Bhatt et al., 2013), and its control is therefore an objective to prevent the transmission of these diseases. Chemical insecticides are still the most important element in mosquito control programs, despite direct and indirect toxic effects on nontarget organisms, including humans. In addition, chemicals induce resistance in a number of vector species (Vontas, Ranson \& Alphey, 2010; Ranson \& Lissenden, 2016; Smith, Kasai \& Scott, 2016). Therefore, there is a need for alternative nonchemical vector control approaches. Classical biological control based on using various microorganisms, such as entomopathogenic fungi and bacteria, is a frequent tool for addressing this issue.

Among the biological agents employed for mosquito larvae control, bacteria from the genus Bacillus are the most widely used. In addition, products of the entomophatogenic fungi Metarhizium anisopliae s.l., and Beauveria bassiana s.l. are actively being developed for use against mosquito adults and larvae (Butt et al., 2013; Greenfield et al., 2015; Ortiz-Urquiza et $a l ., 2015)$. It should be noted that mosquitoes and other insects can develop resistance to the Bacillus thuringiensis biological larvicide (Tilquin et al., 2008; Paris et al., 2011; Boyer et al., 2012). However, the resistance of insects to entomopathogenic fungi develops very slowly (Dubovskiy et al., 2013). Various species of mosquito larvae present different susceptibilities to Metarhizium, among which Ae. aegypti is the least susceptible (Greenfield et al., 2015; GarridoJurado et al., 2016). Thus, a concentration of conidia that is effective for Ae. aegypti control would affect a range of nontarget aquatic invertebrates. Recent studies have found that some nontarget aquatic species are more sensitive to fungal metabolites (Garrido-Jurado et al., 2016) and conidia (Belevich et al., 2017) than target mosquito species. To reduce toxic effects on the 
60 aquatic environment and increase efficacy against mosquitoes, entomopathogenic fungi may be

61 combined with other biocontrol agents or low doses of natural insecticides. For example,

62 combined treatment with Metarhizium and mosquito predator species (Toxorhynchites) has

63 shown additive or synergistic effects on the mortality of Ae. aegypti (Alkhaibari et al., 2018).

64 However, few studies have been carried out to determine the effect of combined treatment with

65 entomopathogenic fungi and other insecticides or plant or microbial metabolites as a potential

66 tool for improving mosquito larvae control. Synergistic effects between entomopathogenic fungi

67 and some chemical insecticides (temephos, spinosad) (Shoukat et al., 2018; Vivekanandhan et

68 al., 2018) or biological agents (Azadirachta indica) (Badiane et al., 2017) on the mortality of

69 mosquito larvae have been found. However, the physiological and biochemical aspects of this

70 synergism were not considered.

71 One type of promising insecticide that can be effectively used for mosquito vector control is the

72 avermectins. Avermectins are a class of macrocyclic lactones isolated from the soil actinomycete

73 Streptomices avermitilis (Drinyaev et al., 1999) and include several commercial derivatives

74 (ivermectin, abamectin, doramectin and eprinomectin) with the same mode of action - activation

75 of glutamate-gated chloride channels, followed by uncontrolled influx of chloride ions into the

76 cells, which leads to paralysis and death of the organism (Campbell et al., 1983). At the same

77 time, avermectins are relatively safe for humans (Crump \& Omura, 2011). Previous studies have

78 shown that avermectins are efficient for the control of Culex quinquefasciatus (Freitas et al.,

79 1996; Alves et al., 2004), Anopheles albimanus, An. stephensi (Dreyer, Morin \& Vaughan,

80 2018), and An. gambiae (Alout et al., 2014; Chaccour et al., 2017). However, most of these

81 studies have been carried out with adult mosquitoes feeding on blood containing ivermectin.

82 Avermectins exhibit a relatively short half-life period, which limits their ability to kill

83 mosquitoes but may be compensated by the application of multiple treatments or use of higher

84 concentrations. However, these approaches may contribute to the development of mosquito

85 larvae resistance to avermectins (Su et al., 2017). We hypothesize that the interaction of

86 entomopathogenic fungi with avermectins can have a stable insecticidal effect at relatively low

87 concentrations and is a promising combination for safe and effective mosquito control.

88 It is important that entomopathogenic fungi such as Metarhizium are adapted to terrestrial hosts

89 and that in mosquito larvae, the fungi do not adhere to the cuticle surface and do not germinate

90 through integuments into the hemocoel. Conidia ingested by mosquito larvae do not penetrate the

91 gut wall (Butt et al., 2013). Thus, a "classic" host-pathogen interaction does not occur, and larval

92 mortality is associated with stress induced by spore-bound proteases on the surface of ingested

93 conidia (Butt et al., 2013). These authors suggest that fungal proteases cause an increase in the

94 activity of caspases in mosquitoes, which leads to apoptosis, autolysis of tissues and death of the

95 larvae. The activation of detoxifying enzymes and antimicrobial peptides (AMPs) occurs in

96 larvae infected with the fungus but is not sufficient to protect the larvae from death. As a rule,

97 mosquito larvae die showing symptoms of bacterial decomposition after treatment with

98 Metarhizium and Beauveria (Scholte et al., 2004). Therefore, this pathogenesis can be considered

99 mixed (both bacterial and fungal).

100 During this process, particular superfamilies of enzymes such as glutathione-S-transferases

101 (GST) and nonspecific esterases (EST) are usually involved in the biochemical transformation of

102 xenobiotics (Li, Schuler \& Berenbaum, 2007). Various hormones such as biogenic amines are

103 involved in insect stress reactions. Among them, the role of the neurotransmitter dopamine

104 (which serves as a neurohormone as well) in this process remain poorly understood. It is known

105 that dopamine mediates phagocytosis and is involved in the activation of the pro-phenoloxidase

Peer) reviewing PDF | (2019:07:39198:1:1:NEW 11 Sep 2019) 
106 (proPO) cascade, thus playing an important role in fungal and bacterial pathogenesis as well as in 107 the development of toxicoses caused by insecticides (Delpuech, Frey \& Carton, 1996; Gorman,

108 An \& Kanost, 2007; Wu et al., 2015). In addition, both pathogens and toxicants can lead to

109 changes in the antimicrobial activity of insects and the bacterial load that can affect the

110 susceptibility of insects to pathogenic fungi (Wei et al., 2017; Ramirez et al., 2018; Polenogova

111 et al., 2019). It should be noted that the above mentioned physiological reactions in mosquito

112 larvae under the combined action of entomopathogenic fungi and insecticides have not yet been

113 studied.

114 The aims of this study were (1) to determine the susceptibility of Aedes aegypti larvae to

115 combined treatment with avermectins and Metarhizium robertsii and (2) estimate their immune

116 and detoxificative responses to $M$. robertsii and avermectins either alone or their combination.

\section{Materials \& methods}

\section{Insecticides and fungi}

119 The entomopathogenic fungus Metarhizium robertsii (strain MB-1) from the collection of

120 microorganisms of the Institute of Systematics and Ecology of Animals SB RAS was used in this work. The conidia of the fungus were grown on autoclaved millet for 10 days at $26^{\circ} \mathrm{C}$ in the dark, followed by drying and sifting (Belevich et al., 2017). The industrial product "Phytoverm" $0.2 \%$ (SPC "Pharmbiomed", Russia) was used in these experiments and includes a complex of natural avermectins (A1a (9\%), A2a (18\%), B1a (46\%), B2a (27\%)) produced by

125 Streptomyces avermitilis.

126 Insect maintenance and toxicity tests

127 Aedes aegypti larvae from the collection of the Institute of Systematics and Ecology of Animals

128 SB RAS were maintained in tap water in the laboratory at $24^{\circ} \mathrm{C}\left( \pm 1^{\circ} \mathrm{C}\right)$ under a natural

129 photoperiod (approximately 16:8 light : dark). The larvae were fed Tetramin Junior fish food

130 (Tetra, Germany). The susceptibility of Ae. aegypti to both avermectins and the conidia of $M$.

131 robertsii was tested in $200 \mathrm{ml}$ plastic containers containing $100 \mathrm{ml}$ of water with 15 larvae.

132 Third-4th-instar larvae were used in the experiment. The experiment involved four treatments:

133 control, fungus, avermectins, and fungus + avermectins. The fungal conidia and avermectins

134 were suspended in distilled water, vortexed and applied separately or together to the containers

135 with mosquito larvae at a volume of $2 \mathrm{ml}$ per container. The final conidial concentration for

136 infection was $1 \times 10^{6}$ conidia / $\mathrm{ml}$. The final concentration of avermectins was $0.00001 \% / \mathrm{ml}$.

137 The control was treated with the same amount of distilled water. Mortality was assessed daily for

1386 days. Ten replicates with 15 larvae were performed for each treatment.

\section{Light microscopy and colonization assessment}

140 Forty-eight hours posttreatment (pt), mosquito larvae ( $\mathrm{n}=3$ for each treatment) were collected in

$1412 \%$ glutaraldehyde containing $0.1 \mathrm{M} \mathrm{Na}$-cacodylate buffer $(\mathrm{pH} 7.2)$ and were maintained at $4{ }^{\circ} \mathrm{C}$

142 for 1-24 h. Semi-thin sections were stained with crystal violet and basic fuchsin and were

143 observed with a phase-contrast microscope (Axioskop 40, Carl Zeiss, Germany).

144 To assess fungal colonization, $48 \mathrm{~h} \mathrm{pt}$ and newly dead larvae (4-6 days pt) were cut open, and 145 their internal contents were squeezed onto a glass side. The contents were examined for the 146 presence / absence of hyphal bodies using light microscopy ( $\mathrm{n}=30$ for each treatment). Newly

147 dead larvae were placed on moistened filter paper in Petri dishes $(n=30)$ to determine the

148 germination and surface sporulation of Metarhizium. 
149 Total larval body supernatant

150 Mosquito larvae bodies of individual 4th-instar larvae of Ae. aegypti were collected in $50 \mu 1$ of

$151 \operatorname{cool}\left(+4{ }^{\circ} \mathrm{C}\right) 0.01 \mathrm{M}$ PBS $(50 \mathrm{mM}, \mathrm{pH} 7.4,150 \mathrm{mM} \mathrm{NaCl})$ with $0.1 \mathrm{mM}$ N-phenylthiourea

152

153 (PTU) to measure GST, EST and acid protease activities or without PTU to measure phenoloxidase (PO) activity. Then, the samples were sonicated in an ice bath with three $10 \mathrm{~s}$ bursts using a Bandelin Sonopuls sonicator. The sample solution was centrifuged at $20.000 \mathrm{~g}$ for $5 \mathrm{~min}$ at $+4{ }^{\circ} \mathrm{C}$. The obtained supernatant was directly used to determine enzyme activities.

\section{Detection of phenoloxidase, glutathione-S-transferase and esterase activity}

157 The activities of PO, GST and EST were measured at 12 and $48 \mathrm{~h}$ after exposure ( $\mathrm{n}=20$ per 158 treatment for each enzyme).

159 PO activity was assayed by using a method modified from that described by Ashida \& Söderhäll 160 (1984). The PO activity of the larval homogenates was determined spectrophotometrically on the 161 basis of the formation of dopachrome at a wavelength of $490 \mathrm{~nm}$. Aliquots of the samples $(10 \mu \mathrm{l})$ were added to microplate wells containing $200 \mu \mathrm{l}$ of $10 \mathrm{mM}$ 3.4-dihydroxyphenylalanine and incubated at $28^{\circ} \mathrm{C}$ in the dark for $45 \mathrm{~min}$. The PO activity was measured kinetically every 5 minutes and the time point was chosen according to Michaelis constant. The activity of EST was measured using the method of Prabhakaran \& Kamble (1995) with some modifications. Aliquots of the samples $(3 \mu \mathrm{l})$ were added to microplate wells containing $200 \mu 1$ of $0.01 \% \mathrm{p}$-nitrophenylacetate and incubated for $10 \mathrm{~min}$ at $28^{\circ} \mathrm{C}$. The activity of EST was determined spectrophotometrically at a wavelength of $410 \mathrm{~nm}$ on the basis of the formation of nitrophenyl. The EST activity was measured kinetically every 2 minutes and the time point was chosen according to Michaelis constant.

The measurement of GST activity was carried out according to the method of Habig et al. (1974) with some modifications. Aliquots of the samples $(7 \mu \mathrm{l})$ were added to microplate wells containing $200 \mu \mathrm{l}$ of $1 \mathrm{mM}$ glutathione and $5 \mu \mathrm{l}$ of $1 \mathrm{mM} 2.4$-Dinitrochlorobenzene and incubated at $28^{\circ} \mathrm{C}$ for $12 \mathrm{~min}$. The activity of GST was determined spectrophotometrically on the basis of the formation of 5-(2.4-dinitrophenyl)-glutathione at a $340 \mathrm{~nm}$ wavelength. The GST activity was measured kinetically every 3 minutes and the time point was chosen according to Michaelis constant.

178 Enzymes activity was measured in units of the transmission density $(\Delta \mathrm{A})$ of the incubation mixture during the reaction per $1 \mathrm{~min}$ and $1 \mathrm{mg}$ of protein. The protein concentration in the samples was determined by the method of Bradford (1976). To generate the calibration curve, bovine serum albumin was used.

\section{Dopamine concentration measurements}

183 Dopamine concentrations were measured at the 12 and $48 \mathrm{~h} \mathrm{pt}$ in individual larval bodies $(\mathrm{n}=10$ per treatment). Mosquito larvae were homogenized in $30 \mu \mathrm{l}$ of phosphate buffer and incubated in a Biosan TS 100 Thermoshaker for 10 minutes at $28^{\circ} \mathrm{C}$ and $600 \mathrm{rpm}$, then incubated at room temperature for 20 minutes and centrifuged at $4{ }^{\circ} \mathrm{C}$ and $10.000 \mathrm{~g}$ for 10 minutes. The supernatants were transferred to clean tubes and centrifuged with the same settings for 5 minutes. Before transfer to the chromatograph, the samples were filtered.

Dopamine concentrations were measured by an external standard method using an Agilent 1260 Infinity high-performance liquid chromatograph with an EsaCoulochem III electrochemical detector (cell model 5010A, potential $300 \mathrm{mV}$ ) according to the method of Gruntenko et al. (2005) with some modifications. Dopamine hydrochloride (Sigma-Aldrich) was used as a standard. Separation was performed in a ZorbaxSB-C18 column $(4.6-250 \mathrm{~mm}$, particles $5 \mu \mathrm{m})$ in 
194 isocratic mode. Mobile phase: $90 \%$ buffer (200 mg/l 1-OctaneSulfonicAcid (Sigma-Aldrich),

$\left.1953.5 \mathrm{~g} / 1 \mathrm{KH}_{2} \mathrm{PO}_{4}\right)$ and $10 \%$ acetonitrile. The flow rate was $1 \mathrm{ml} / \mathrm{min}$. Chromatogram processing

196 was performed using ChemStation software, and the amount of dopamine was determined by

197 comparing the peak areas of the standard and the sample.

\section{Acid proteases}

199 Acid protease activity was measured using method described by Anson (1983) with

200 modifications. Fifty $\mu 1$ of the homogenate supernatant was added to $250 \mu 1$ of $0.1 \mathrm{M}$ acetate

201 buffer ( $\mathrm{pH}$ 4.6) containing $0.3 \%$ hemoglobin (Sigma, CAS number 9008-02-0). The samples

202 were incubated for $60 \mathrm{~min}$ at $27^{\circ} \mathrm{C}$, and the reaction was stopped by adding $500 \mu 1$ of $5 \%$ TCA

203 and cooling on ice for $10 \mathrm{~min}$ at $4{ }^{\circ} \mathrm{C}$. The samples were centrifuged at $14000 \mathrm{~g}$ for $5 \mathrm{~min}$ at 4

$204{ }^{\circ} \mathrm{C}$, and the enzyme activity was determined spectrophotometrically at a wavelength of $280 \mathrm{~nm}$

205 in a 96-well plate reader.

206 Lysozyme-like activity

207 Lysozyme-like activity in the mosquito homogenate was determined through analysis of the lytic

208

209

210

211

212

213

214

215

216

217

218

219

220

221

222

223

224

225

226

227

228

229

230 zone by diffusion into agar. Ten milliliters of Nutrient Agar (NA) (HiMedia, India) and Micrococcus lysodeikticus bacteria $\left(1 \times 10^{7}\right.$ cells $\left./ \mathrm{ml}\right)$ were added to Petri dishes. The agar was perforated to create $2 \mathrm{~mm}$-diameter wells, which were then filled with $3 \mu \mathrm{l}$ of full-body homogenate, followed by incubation at $37^{\circ} \mathrm{C}$ for $24 \mathrm{~h}$. Series of dilutions of chicken egg white lysozyme (EWL) (Sigma) $(0.5 \mathrm{mg} / \mathrm{ml}, 0.2 \mathrm{mg} / \mathrm{ml}, 0.1 \mathrm{mg} / \mathrm{ml}, 0.005 \mathrm{mg} / \mathrm{ml}, 0.001 \mathrm{mg} / \mathrm{ml}$ ) were added to each dish, allowing us to obtain a calibration curve based on these standards. Lytic activity was determined by measuring the diameter of the clear zone around each well and expressed as the equivalent of EWL (mg / ml) (Mohrig \& Messner, 1968).

\section{CFU counts of Metarhizium and cultivated bacteria in infected larvae}

Homogenates of the mosquitoes ( 3 larvae per sample) were suspended in $1 \mathrm{ml}$ of sterile aqueous Tween-20 (0.03\%), and the suspensions were then diluted 50-fold. Next, $100 \mu 1$ aliquots were inoculated onto the surface of modified Sabouraud agar (10 g peptone, $40 \mathrm{~g}$ D-glucose anhydrous, $20 \mathrm{~g}$ agar, $1 \mathrm{~g}$ yeast extract) supplemented with an antibiotic cocktail (acetyltrimethyl ammonium bromide $0.35 \mathrm{~g} / \mathrm{L}$; cycloheximide $0.05 \mathrm{~g} / \mathrm{L}$; tetracycline $0.05 \mathrm{~g} / \mathrm{L}$; streptomycin $0.6 \mathrm{~g} / \mathrm{L}$; PanReacAppliChem, Germany) for the inhibition of bacteria and saprotrophic fungi. The Petri dishes were maintained at $28{ }^{\circ} \mathrm{C}$ in the dark. The colonies were then counted after 7 days.

For the estimation of cultivated bacterial CFU counts, homogenates of larvae (3 larvae per sample) were suspended in $1 \mathrm{ml}$ of $0.1 \mathrm{M}$ phosphate buffer. Then, the suspension was diluted to $10^{-2}, 10^{-3}$ and $10^{-4}$. Aliquots of $100 \mu \mathrm{l}$ of the larval dilutions were inoculated onto the surface of blood agar media (HiMedia, India). The Petri dishes were maintained at $28{ }^{\circ} \mathrm{C}$. The colonies were counted after $48 \mathrm{~h}$. Three samples of each treatment were used in the analysis.

Statistical analysis

231 Data were analyzed using GraphPad Prism v.4.0 (GraphPad Software Inc., USA), Statistica 8

232

233

234

235

236

237

238 (StatSoft Inc., USA), PAST 3 (Hammer, Harper, Ryan, 2001) and AtteStat 12.5 (Gaidyshev, 2004). Differences between synergistic and additive effects were determined by comparing the expected and observed insect mortality using the $\chi^{2}$ criterion (Tounou et al., 2008). The expected mortality from dual treatment was calculated by the formula $\mathrm{P}_{\mathrm{E}}=\mathrm{P}_{0}+\left(1-\mathrm{P}_{0}\right) \times\left(\mathrm{P}_{1}\right)+\left(1-\mathrm{P}_{0}\right) \times$ $\left(1-\mathrm{P}_{1}\right) \times\left(\mathrm{P}_{2}\right)$, where $\mathrm{P}_{\mathrm{E}}$ is the expected mortality after combined treatment with fungus and avermectins, $\mathrm{P}_{0}$ is mortality in the control groups, $\mathrm{P}_{1}$ is the mortality posttreatment with $M$. robertsii, $\mathrm{P}_{2}$ is the mortality posttreatment with avermectins. The $\chi^{2}$ values were calculated by 
239 the formula $\chi^{2}=\left(\mathrm{L}_{0}-\mathrm{L}_{\mathrm{E}}\right)^{2} / \mathrm{L}_{\mathrm{E}}+\left(\mathrm{D}_{0}-\mathrm{D}_{\mathrm{E}}\right)^{2} / \mathrm{D}_{\mathrm{E}}$, where $\mathrm{L}_{0}$ is the observed number of survived

240 larvae, $\mathrm{L}_{\mathrm{E}}$ is the expected number of surviving larvae, $\mathrm{D}_{0}$ is the observed number of dead larvae,

241

242

243

244

245

246

247

248

249

250

251

252

253

254

255

256

257

258

259

260

261

262

263

264

265

266

267

268

269

270

271

272

273

274

275

276

277

278

279

280

281

282 and $\mathrm{D}_{\mathrm{E}}$ is the expected number of dead larvae. This formula was used to test the hypothesis of independence ( $1 \mathrm{df}: \mathrm{P}=0.05)$. Additive effect was indicated if $\chi^{2}<3.84$. A synergistic effect was indicated if $\chi^{2}>3.84$ and observed mortality greater than the expected one. A value of 3.84 corresponds to $\mathrm{P}<0.05$ with a degree of freedom $=1$. The Kaplan-Meier test was used to calculate the median lethal time (presented as LT50 $\pm \mathrm{SE}$ ). A log-rank test was used to quantify differences in mortality dynamics. As the distribution of the physiological parameters except for the dopamine concentration deviated from a normal distribution (Shapiro-Wilk test, $\mathrm{P}<0.05$ ), we used the nonparametric equivalent of a two-way ANOVA: the Scheirer-Ray-Hare test (Scheirer et al., 1976), followed by Dunn's post hoc test. The data on dopamine concentrations passed the normality test (Shapiro-Wilk test, P $>0.05$ ) and were analyzed by two-way ANOVA followed by Tukey's post hoc test. Differences between Metarhizium CFU counts were compared by t-tests.

\section{Results}

\section{Synergy between avermectins and the fungus}

Significant differences in the dynamics of larval mortality between the treatments were observed (log-rank test: $\chi^{2}=397.3, \mathrm{df}=3, \mathrm{P}<0.0001$; Fig. 1). Treatment with avermectins or conidia of M. robertsii led to 57 and $55 \%$ mortality, respectively, whereas combined treatment led to $99 \%$ mortality at the 6 th day postinfection. Mortality in the control treatment did not exceed $1 \%$. The median lethal time post-combined treatment $(3 \pm 0.1 \mathrm{~d})$ occurred twice as fast as under treatment with avermectins $(6 \pm 0.3 \mathrm{~d})$ or the fungus $\left(6 \mathrm{~d} \pm\right.$ inf.) alone $\left(\chi^{2}>113.7, \mathrm{df}=1, \mathrm{P}<0.0001\right)$. From the 2 nd to the 6th day pt, the avermectins and fungus interacted synergistically $\left(\chi^{2}>18.5\right.$, $\mathrm{df}=1, \mathrm{P}<0.001$, ESM Table S1). These effects were consistently observed in four independent experiments.

\section{Colonization assay}

At $48 \mathrm{~h} \mathrm{pt}$, we observed mass accumulation of Metarhizium conidia in the gut lumen (Fig. 2A). Germinated conidia were not detected in larvae at $48 \mathrm{~h} \mathrm{pt}(\mathrm{n}=12)$. However, in one sample (combined treatment), hyphal bodies were detected in the hemocoel (Fig. 2A). In the newly dead larvae after the fungal and combined treatments (4-6 days), we detected colonization of the hemocoel with hyphal bodies (Fig. 2B). Under the combined treatment, $83 \%$ hypha-positive larvae were found, while in the fungal treatment, $90 \%$ hypha-positive larvae were recorded. No significant differences between these treatments were observed $\left(\chi^{2}=0.58, \mathrm{df}=1, \mathrm{P}=0.45, \mathrm{n}=\right.$ 30 larvae per treatment). No hyphal bodies were detected in the fungus-free treatments. A total of $70 \%$ and $60 \%$ of larvae were overgrown with Metarhizium under incubation in moist chambers (Fig. 2C) after treatment with the fungus or the mixture (avermectins + fungus), respectively. Only nongerminated conidia, but no hyphal bodies, were detected in the water in which treated larvae were maintained (Fig. 2D).

\section{Phenoloxidase activity}

At $12 \mathrm{~h} \mathrm{pt}$, we registered a significant decrease in $\mathrm{PO}$ activity under the influence of fungal infection (Scheirer-Ray-Hare test, effect of fungus: $\mathrm{H}_{1.52}=12.6, \mathrm{P}=0.00038$; Fig. 3).

Avermectins did not significantly change $\mathrm{PO}$ activity $\left(\mathrm{H}_{1.52}=0.3, \mathrm{P}=0.54\right)$. A stronger decrease in enzyme activity was observed after combined treatment, but a significant factor interaction was not revealed $\left(\mathrm{H}_{1.52}=1.9, \mathrm{P}=0.16\right)$. At $48 \mathrm{~h} \mathrm{pt}$, we detected a significant increase in PO 
283

284

285

286

287

288

289

290

291

292

293

294

295

296

297

298

299

300

301

302

303

304

305

306

307

308

309

310

311

312

313

314

315

316

\section{7}

318

319

320

321

322

323

324

325

326

activity under the influence of avermectins $\left(\mathrm{H}_{1.32}=5.33, \mathrm{P}=0.02\right)$. The effect of the fungus was not significant $\left(\mathrm{H}_{1.32}=0.7, \mathrm{P}=0.39\right)$, but a tendency toward an interaction between the factors was revealed $\left(\mathrm{H}_{1.32}=3.2, \mathrm{P}=0.07\right)$. This is explained by the inhibition of $\mathrm{PO}$ activity by the fungus alone (Dunn's test, $\mathrm{P}=0.01, \mathrm{P}=0.04$, compared to the control and avermectin treatments, respectively) and by the tendency of increased enzyme activity after combined treatment.

\section{Dopamine concentration}

The effects of the fungus or avermectins on the dopamine concentration at $12 \mathrm{~h} \mathrm{pt}$ were not significant $\left(\mathrm{F}_{1.31}=1.2, \mathrm{P}=0.27\right.$; Fig. 4$)$, although a trend toward a factor interaction was revealed $\left(\mathrm{F}_{1.31}=3.3, \mathrm{P}=0.07\right)$. This was due to a clear tendency to decrease the dopamine concentration after treatment with the fungus alone (HSD Tukey test, $\mathrm{P}=0.07$ compared to fungus-free treatments) but not with the combination of the fungus and avermectins $(\mathrm{P}=0.47$ compared to fungus-free treatments). At $48 \mathrm{~h} \mathrm{pt}$, we observed a significant decrease in the dopamine concentration under the influence of the fungus $\left(\mathrm{F}_{1.31}=4.62, \mathrm{P}=0.03\right)$; however, there were no significant differences between the treatments (HSD Tukey test, $p=0.1$ ). No significant interaction effects between the factors on the dopamine concentration at $48 \mathrm{~h} \mathrm{pt}$ were detected $\left(\mathrm{F}_{1.31}=0.0, \mathrm{P}=1.0\right)$.

\section{Detoxifying enzymes}

At $12 \mathrm{~h} \mathrm{pt}$, an interaction effect between the two factors (avermectins and the fungus) on GST activity was observed $\left(\mathrm{H}_{1.44}=8.1, \mathrm{P}=0.0043\right.$, Fig. 5A). Avermectins and the fungus alone significantly (1.5-2-fold) increased GST activity compared to untreated larvae (Dunn's test, $\mathrm{P}=$ $0.007, \mathrm{P}=0.001$, respectively), but after combined treatment, the enzyme activity did not significantly differ from that in the control. Similar patterns were registered for EST activity at $12 \mathrm{~h} \mathrm{pt}$ (Fig. 5B). In this case, EST was activated under the influence of avermectins alone (Dunn's test, $\mathrm{P}=0.002$, compared to control), but fungal infection inhibited this activation. In particular, EST activity in the fungal and combined treatments did not differ from that in the control (Dunn's test, $\mathrm{P}=0.28, \mathrm{P}=0.34$, respectively).

At $48 \mathrm{~h} \mathrm{pt}$, we observed a significant increase in GST activity under the influence of avermectins $\left(\mathrm{H}_{1.32}=4.2, \mathrm{P}=0.03\right)$. The effect of the fungus as well as the interaction between the factors on GST activity at this time point was not significant $\left(\mathrm{H}_{1.32}=2.5, \mathrm{P}=0.1\right.$ and $\mathrm{H}_{1.32}=0.61, \mathrm{P}=0.43$, respectively). EST activity nonsignificantly increased under the influence of avermectins $\left(\mathrm{H}_{1.32}=\right.$ $1.85, \mathrm{P}=0.17)$. The effect of the fungus on enzyme activity was not significant $\left(\mathrm{H}_{1.32}=0.001, \mathrm{P}\right.$ $=0.96)$, and no significant interactions between the factors were detected $\left(\mathrm{H}_{1.32}=0.49, \mathrm{P}=\right.$ $0.48)$.

\section{Acid protease activity}

At $12 \mathrm{~h} \mathrm{pt}$, a significant interaction between avermectins and the fungus on acid protease activity was observed $\left(\mathrm{H}_{1.48}=14.8 ; \mathrm{P}=0.00011 ;\right.$ Fig. 6$)$. In particular, protease activity was increased after fungal treatment alone (3-fold compared to control, $\mathrm{P}=0.0003$ ) but not after combined treatment. At $48 \mathrm{~h} \mathrm{pt}$, protease activity was strongly increased under the influence of avermectins $\left(\mathrm{H}_{1.43}=27.4, \mathrm{P}=0.000016\right)$, and a trend toward an increase in enzyme activity was registered under the influence of the fungus $\left(\mathrm{H}_{1.43}=3.18, \mathrm{P}=0.07\right)$. No significant interaction between the factors was revealed, although a trend toward the highest increase in protease activity was registered after the combined treatment.

\section{Lysozyme-like activity}


327 At $12 \mathrm{~h} \mathrm{pt}$, we recorded a decrease in lysozyme-like activity under the influence of both fungal

328 infection and avermectins (effect of fungus: $\mathrm{H}_{1.56}=6.46, \mathrm{P}=0.011$; effect of avermectins: $\mathrm{H}_{1.56}$ $329=14.04, \mathrm{P}=0.00017$; Fig. 7). The greatest decrease was observed after the combined treatment

330 (Dunn's test, $\mathrm{P}<0.001$, compared with the other treatments). At $48 \mathrm{~h} \mathrm{pt}$, a sharp (1.7-2.0-fold)

331 increase in lysozyme-like activity was recorded under the influence of avermectins $\left(\mathrm{H}_{1.116}=\right.$

$33268.6, \mathrm{P}<0.0000001)$. The effect of the fungus on the level of the enzyme at $48 \mathrm{~h} \mathrm{pt}$ was not

333 significant. No significant interaction effect between the factors on the level of lysozyme was

334 observed at 12 and $48 \mathrm{~h} \mathrm{pt}(\mathrm{H}=0.23, \mathrm{P}=0.63)$.

\section{Fungal and bacterial CFUs}

336 The plating of mosquito larval homogenates on modified Sabouraud agar showed significant differences in the Metarhizium CFUs between treatment with the fungus either alone or combined with avermectins (Fig. 8A). The Metarhizium CFU count in the fungal treatment was twice as high as that in the combined treatment $(\mathrm{t}=6.4, \mathrm{df}=18, \mathrm{P}=0.001)$. Homogenates of the larvae from the fungus-free treatments (avermectin alone and control) did not form any fungal colonies.

342 The plating of larval homogenates on blood agar showed a significant (17-75-fold) increase in bacterial CFUs after treatment with the fungus and avermectins. A significant effect was registered for avermectins $\left(\mathrm{H}_{1.19}=4.8, \mathrm{P}=0.03\right.$; Fig. $\left.8 \mathrm{~B}\right)$ but not for the fungus $\left(\mathrm{H}_{1.19}=1.9, \mathrm{P}=\right.$ 0.17). However, a clear tendency toward an increase in CFUs was registered after treatment with the fungus alone (Dunn's test, $\mathrm{P}=0.054$, compared to control). No significant interaction effect between the fungus and avermectins on bacterial CFUs was revealed $\left(\mathrm{H}_{1.19}=1.9, \mathrm{P}=0.17\right)$.

\section{Discussion}

350

We showed a synergistic effect between avermectins and Metarhizium fungi on aquatic invertebrates for the first time. A similar effect was shown previously only in terrestrial insects (Colorado potato beetle, cotton moth) (Anderson et al., 1989; Asi et al., 2010; Tomilova et al., 2016), which are characterized by a completely different mode of fungal penetration (through the exo-skeleton). The accumulation of conidia of the fungus mainly in the gut lumen of mosquitoes coincides with studies of other researchers (Butt et al., 2013). However, we report the first observation of colonization of Ae. aegypti larvae after inoculation with Metarhizium conidia. It was previously suggested that only blastospores (and not conidia) are able to germinate from the gut lumen into the hemocoel of mosquito larvae (Alkhaibari et al., 2016, 2018). Interestingly, the larvae treated with avermectins accumulated a lower amount of conidia, but this dose was sufficient for a synergistic effect on mortality. It is likely that reduced accumulation of conidia was due to disturbance of feeding. For example, decrease in quantity of consumed food under the influence of avermectins was shown for terrestrial insects (Akhanaev et al., 2017).

We observed a decrease in PO activity and dopamine levels under the influence of the fungus, whereas in terrestrial arthropods, these enzymes are activated during mycoses ( Ling \& Yu, 2005; Yassine, Kamareddine \& Osta, 2012; Yaroslavtseva et al., 2017; Chertkova et al., 2018). It has been suggested that dopamine release is associated with the general stress reactions related to the insect's responses to pathogens (Hirashima, Sukhanova \& Rauschenbach, 2000; Chertkova et $a l ., 2018$ ). In addition, dopamine is involved in the modulation of energetic metabolism and general defense mechanisms such as phagocytosis ( $W u$ et al., 2015). PO is involved in the inactivation of fungal propagules in the cuticle and hemocoel (Butt et al., 2016). Dopamine is involved in the PO cascade (Andersen, 2010); however, synchronous and unidirectional changes in the levels of PO and dopamine are not always observed during infections (Chertkova, 2016,

372 unpublished data). Since we observed differentiation of fungal infection structures, we suggest 
373 that some fungal metabolites inhibit the PO cascade of Ae. aegypti larvae. It was shown on

374 terrestrial insects that Metarhizium secondary metabolites (e.g. destruxins) may reduce the

375 number of PO-positive hemocytes (Huxham, Lackie, \& McCorkindale, 1989) and these

376 metabolites may upregulate serine protease inhibitors, which inhibit proPO cascade (Pal, Leger

$377 \& W u$, 2007). Alkhaibari et al. (2018) noted a short-term increase in PO activity in the whole-

378 body homogenates of Culex quinquefasciatus larvae after infection with conidia or blastospores

379 of M. brunneum (4-6 h pt). It is possible that this reaction depends on species of mosquitoes as

380 well as strain of the pathogen. Especially, inhibition of hemolymph melanization under $M$.

381 robertsii infections was dependent from production of secondary metabolites by different strains

382 (Wang et al. 2012).

383 We observed activation of detoxifying enzymes (GST, EST) in Ae. aegypti larvae at the early

384 stages of toxicosis and infection $(12 \mathrm{~h} \mathrm{pt})$ under mono-treatments with the fungus and

385 avermectins. However, the combined treatment led to inhibition of the activation of GST and

386 EST. A similar effect was observed at $12 \mathrm{~h} \mathrm{pt}$ for antibacterial (lysozyme-like) and acid protease

387 activities. Combined treatment leads to either inhibition or containment of the activation of these

388 enzymes. GST and EST are used by insects to inactivate toxic products formed by insecticide-

389 induced toxicoses (DeSilva et al., 1997; Boyer et al., 2006; Aponte et al., 2013) as well as under

390 mycosis (Dubovskiy et al., 2012). Especially Tang et al. (2019) shown that up-regulation of

391 GSTz2 decreased the susceptibility of tephritid fruit fly Bactrocera dorsalis (Hendel) to

392 abamectin. Moreover, GST may participate in inactivation of fungal secondary metabolites

393 (Loutelier \& Cherton, 1994) and reactive oxygen species (Sherratt \& Hayes, 2002). Lysozyme

394 inhibits the reproduction of Gram-positive bacteria (Abdou et al., 2007; Gandhe et al., 2007;

395 Chapelle et al., 2009), which (e.g., Microbacteriaceae) are among the dominant bacteria in $\mathrm{Ae}$.

396 aegypti larvae (Coon et al., 2014). It should also be noted that at $12 \mathrm{~h} \mathrm{pt}$ of Ae. aegypti with

397 blastospores of M. brunneum, a decrease in the expression levels of genes encoding defensins

398 and cecropins (Alkhaibari et al., 2016), which inhibit the growth of both Gram-positive and

399 Gram-negative bacteria and fungi, was observed (Jozefiak et al., 2017). The inhibition of acid

400 protease activity under combined treatment may indicate disorders in food consumption and

401 absorption. Disruption of food absorption and starvation can increase mortality from both fungi

402 and insecticides (Furlong \& Groden, 2003). Thus, we assume that the physiological causes of

403 the observed synergism lie in the initial stages of the development of infection and toxicosis.

404 In the later stages $(48 \mathrm{~h} \mathrm{pt}$ ), we mainly observed activation of the enzymes (PO, GST, EST, acid

405 proteases and lysozyme-like activity), which apparently indicates destructive processes in tissues

406 and organs under the action of both avermectins and fungi. The increase in PO activity on the

407 second day after treatment with avermectins was probably due to the destruction of hemocytes

408 and the release of intracellular proPO components. We have previously shown the cytotoxic

409 effect of avermectins on hemocytes, leading to their death (Tomilova et al., 2016). Additionally,

410 the cytostatic and cytotoxic effects of the avermectins complex on various cells of warm-blooded

411 animals are well known (Sivkov et al., 1998; Kokoz et al., 1999; Korystov et al., 1999; Maioli et

412 al., 2013). Increase in PO activity under the influence of avermectins could also be symptom

413 linked with proliferation of bacteria (Fig. 8). The enhancement of PO is observed under

414 development of various bacterioses and caused by damages of insect's tissues as well as by

415 recognition of bacterial cell wall compounds, formation of hemocyte nodules and their

416 melanization (Bidla et al., 2009; Tokura et al. 2014; Dubovskiy et al., 2016). An increase in GST

417 under mycoses usually correlates with the severity of the infectious process (Dubovskiy et al.,

418 2012; Tomilova et al., 2019) and confirms the results obtained by Butt et al. (2013) when

Peer) reviewing PDF | (2019:07:39198:1:1:NEW 11 Sep 2019) 
419 studying the pathogenesis of M. brunneum in Ae. aegypti larvae. An increase in lysozyme-like

420

421

422

423

424

425

426

427

428

429

430

431

432

433

434

435

436

437

438

439

440

441

442

443

444

445

446

447

448

449

450

451

452

453

454

455

456

457

458

459

460

461

462

463

activity under the action of avermectins could have occurred due to tissue destruction accompanied by the release of lysosome contents containing lysozyme (Zachary \& Hoffmann, 1984). The activation of proteases at $48 \mathrm{~h} \mathrm{pt}$ under the influence of avermectins is correlated with the increase in PO and lysozyme-like activity, which also indicates destructive changes in the tissues.

We observed an increase in the number of cultivated bacteria in the larvae when treated with both avermectins and fungi. This effect may be associated with impaired intestinal peristalsis as well as changes in the level of PO and antibacterial activity in the initial stages of toxicosis and fungal infection. Similar effects have been observed in terrestrial insects following topical infection by fungi (Wei et al., 2017; Ramirez et al., 2018; Polenogova et al., 2019) and are associated with the redistribution of immune responses between the cuticle and the gut. In mosquito larvae, the fungus comes into direct contact with gut microbiota, which may exhibit fungistatic properties (Sivakumar et al., 2017; Zhang et al., 2017, etc.) or, alternatively, may act as synergists of fungi, as shown by Wei et al. (2017) in the adults of the mosquito Anopheles stephensi. It is possible that conflicting data on the colonization of mosquito larvae by Metarhizium fungi are associated with differences in bacterial communities, which requires further research. In any case, fungi cannot successfully complete colonization in an aquatic environment, and bacterial decomposition is observed in mosquito larvae, whereas surface conidiation occurs in the air environment.

\section{Conclusions}

In conclusion, this is the first study of the survival and physiological reactions of mosquito larvae under the combined action of avermectins and entomopathogenic fungi. The synergism observed under the combined action of these agents appears to be associated with physiological changes in the early stages of toxicosis and infection. In particular, inhibition of the activity of a number of enzymes is observed under the combined treatment associated with the detoxifying and immune systems.

Colonization of mosquito larvae by the fungus Metarhizium is shown for the first time in this study. Further investigations may be focused on studying the role of endosymbiotic mosquito bacteria in the development of toxicoses and mycoses as well as the development of preparative forms based on fungi and avermectins for mosquito control in natural conditions.

\section{Acknowledgments}

The authors are grateful to Dr. V.A. Shilo (Karasuk Station of the ISEA) for help in organizing the experiments.

\section{References}

Abdou, A.M., Higashiguchi, S., Aboueleinin, A.M., Kim, M., \& Ibrahim, H.R. 2007. Antimicrobial peptides derived from hen egg lysozyme with inhibitory effect against Bacillus species. Food Control, 18(2):173-178. DOI: 10.1016/j.foodcont.2005.09.010.

Akhanaev, Y. B., Tomilova, O. G., Yaroslavtseva, O. N., Duisembekov, B. A., Kryukov, V. Y., \& Glupov, V. V. 2017. Combined action of the entomopathogenic fungus Metarhizium robertsii and avermectins on the larvae of the colorado potato beetle Leptinotarsa decemlineata (Say) (Coleoptera, Chrysomelidae). Entomological Review, 97(2), 158-165. DOI: 10.1134/S0013873817020026.

Alkhaibari, A.M., Carolino, A.T., Yavasoglu, S.I., Maffeis, T., Mattoso, T.C., Bull, J.C., ... \& Butt, T. M. 2016. Metarhizium brunneum blastospore pathogenesis in Aedes aegypti larvae:

Peer] reviewing PDF | (2019:07:39198:1:1:NEW 11 Sep 2019) 
464 attack on several fronts accelerates mortality. PLoS pathogens, 12(7):e1005715. DOI:

465 10.1371/journal.ppat.1005715.

466 Alkhaibari, A.M., Maffeis, T., Bull, J.C., \& Butt, T.M. 2018. Combined use of the

467 entomopathogenic fungus, Metarhizium brunneum, and the mosquito predator, Toxorhynchites

468 brevipalpis, for control of mosquito larvae: Is this a risky biocontrol strategy? Journal of

469 invertebrate pathology, 153:38-50. DOI: 10.1016/j.jip.2018.02.003.

470 Alout, H., Krajacich, B.J., Meyers, J.I., Grubaugh, N.D., Brackney, D.E., Kobylinski, K.C., ... \&

471 Dabiré, R.K. 2014. Evaluation of ivermectin mass drug administration for malaria transmission

472 control across different West African environments. Malaria journal, 13(1):417. DOI:

473 10.1186/1475-2875-13-417.

474 Alves, S.N., Serrão, J.E., Mocelin, G., \& Melo, A.L.D. 2004. Effect of ivermectin on the life

475 cycle and larval fat body of Culex quinquefasciatus. Brazilian archives of biology and

476 technology, 47(3):433-439. DOI: 10.1590/S1516-89132004000300014.

477 Andersen, S.O. 2010. Insect cuticular sclerotization: a review. Insect biochemistry and molecular

478 biology, 40(3):166-178. DOI: 10.1016/j.ibmb.2009.10.007.

479 Anderson, T.E., Hajek, A.E., Roberts, D.W., Preisler, H.K., \& Robertson, J.L. 1989. Colorado

480 potato beetle (Coleoptera: Chrysomelidae): effects of combinations of Beauveria bassiana with

481 insecticides. Journal of Economic Entomology, 82(1):83-89. DOI: 10.1093/jee/82.1.83.

482 Anson, M. L. 1938. The estimation of pepsin, trypsin, papain, and cathepsin with

483 hemoglobin. The Journal of general physiology, 22(1), 79. DOI:10.1085/jgp.22.1.79.

484 Aponte, H.A., Penilla, R.P., Dzul-Manzanilla, F., Che-Mendoza, A., López, A.D., Solis, F., ... \&

485 Rodríguez, A.D. 2013. The pyrethroid resistance status and mechanisms in Aedes aegypti from

486 the Guerrero state, Mexico. Pesticide biochemistry and physiology, 107(2):226-234. DOI:

487 10.1016/j.pestbp.2013.07.005.

488 Ashida, M., \& Söderhäll, K. 1984. The prophenoloxidase activating system in

489 crayfish. Comparative Biochemistry and Physiology Part B: Comparative

490 Biochemistry, 77(1):21-26. DOI: 10.1016/0305-0491(84)90217-7.

491 Asi, M.R., Bashir, M.H., Afzal, M., Ashfaq, M., \& Sahi, S. T. 2010. Compatibility of

492 entomopathogenic fungi, Metarhizium anisopliae and Paecilomyces fumosoroseus with selective

493 insecticides. Pakistan Journal of Botany, 42(6):4207-4214.

494 Badiane, T.S., Ndione, R.D., Toure, M., Seye, F., \& Ndiaye, M. 2017.Larvicidal and Synergic

495 Effects of two Biopesticides (Azadirachta indica and Metarhizium anisopliae) against Larvae of

496 Culex quinquefasciatus (Diptera, Culicidae) (Say, 1823). International Journal of Sciences,

497 6:109-115. DOI: 10.18483/ijSci.1258.

498 Belevich, O.E., Yurchenko, Yu.A., Glupov, V.V., Kryukov, V.Yu. 2017. Effect of

499 entomopathogenic fungus Metarhizium robertsii on non-target organisms, water bugs

500 (Heteroptera: Corixidae, Naucoridae, Notonectidae). Journal of Applied entomology and

501 Zoology, 52:439-445. DOI: 10.1007/s13355-017-0494-z.

502 Bidla, G., Hauling, T., Dushay, M. S., \& Theopold, U. 2009. Activation of insect phenoloxidase

503 after injury: endogenous versus foreign elicitors. Journal of innate immunity, 1(4), 301-308.

504 DOI: 10.1159/000168009.

505 Bhatt S., Gething P.W., Brady O.J., Messina J.P., Farlow A.W., Moyes C.L., Drake J.M., 506 Brownstein J.S., Hoen A.G., Sankoh O., Myers M.F., George D.B., Jaenisch T., Wint G.R.W., 507 Simmons C.P., Scott T.W., Farrar J.J., Hay S.I. 2013. The global distribution and burden of 508 dengue. Nature, 496(7446):504-507. DOI: 10.1038/nature12060. 
509 Boyer, S., David, J.P., Rey, D., Lemperiere, G., \& Ravanel, P. 2006. Response of Aedes aegypti

510 (Diptera: Culicidae) larvae to three xenobiotic exposures: larval tolerance and detoxifying

511 enzyme activities. Environmental Toxicology and Chemistry: An International Journal,

512 25(2):470-476. DOI: 10.1897/05-267R2.1.

513 Boyer, S., Paris, M., Jego, S., Lempérière, G., Ravanel, P. 2012. Influence of insecticide Bacillus

514 thuringiensis subsp. israelensis treatments on resistance and enzyme activities in Aedes rusticus

515 larvae (Diptera: Culicidae). Biol. Control. 62:75-81. DOI: 10.1016/j.biocontrol.2012.02.001.

516 Bradford, M.M. 1976. A rapid and sensitive method for the quantitation of microgram quantities

517 of protein utilizing the principle of protein-dye binding. Analytical biochemistry, 72(1-2):248-

518 254. DOI: 10.1016/0003-2697(76)90527-3.

519 Butt, T.M., Greenfield, B.P., Greig, C., Maffeis, T.G., Taylor, J.W., Piasecka, J., ... \& Quesada-

520 Moraga, E. 2013. Metarhizium anisopliae pathogenesis of mosquito larvae: a verdict of

521 accidental death. PloS one, 8(12):e81686. DOI: 10.1371/journal.pone.0081686.

522 Butt, T.M., Coates, C.J., Dubovskiy, I.M., \& Ratcliffe, N.A. 2016. Entomopathogenic fungi: new

523

524

525

526

527

528

529

530

531

532

533

534 insights into host-pathogen interactions. In Lovett B\& Leger RJSt, eds.Genetics and Molecular Biology of Entomopathogenic Fungi. Academic Press, 307-364.DOI: 10.1016/j.jip.2018.02.020. Campbell, W.C., Fisher, M.H., Stapley, E.O., Albers-Schonberg, G., \& Jacob, T.A. 1983. Ivermectin: a potent new antiparasitic agent. Science, 221(4613):823-828. DOI: 10.1126/science.6308762.

Chaccour, C.J., Hammann, F., Alustiza, M., Castejon, S., Tarimo, B.B., Abizanda, G., ... \& Aldaz, A. 2017. Cytochrome P450/ABC transporter inhibition simultaneously enhances ivermectin pharmacokinetics in the mammal host and pharmacodynamics in Anopheles gambiae. Scientific reports, 7(1):8535. DOI: 10.1038/s41598-017-08906-X.

Chapelle, M., Girard, P.A., Cousserans, F., Volkoff, N.A., \& Duvic, B. 2009. Lysozymes and lysozyme-like proteins from the fall armyworm, Spodoptera frugiperda. Molecular immunology, 47(2-3):261-269. DOI:10.1016/j.molimm.2009.09.028.

535

536

537 Chertkova, E.A., Dubovskiy, I.M., Yaroslavtseva, O.N., Grizanova, E.V., Kryukov, V.Y., Glupov, V.V. 2016. Changes in the dopamine levels of haemolymph of cabbage armyworm Mamestra brassicae L. (Lepidoptera: Noctuidae) and Colorado potato beetle Leptinotarsa decemlineata Say (Coleoptera: Chrysomelidae) at various pathogenesis. Euroasian Entomological Journal, 15(1):60-67. (In Russian).

540 Chertkova, E.A., Grizanova, E.V., \& Dubovskiy, I.M. 2018. Bacterial and fungal infections

541 induce bursts of dopamine in the haemolymph of the Colorado potato beetle Leptinotarsa

542 decemlineata and greater wax moth Galleria mellonella. Journal of invertebrate pathology, 153:203-206. DOI: 10.1016/j.jip.2018.02.020.

544 Coon, K. L., Vogel, K. J., Brown, M. R., \& Strand, M. R. 2014. Mosquitoes rely on their gut microbiota for development. Molecular ecology, 23(11), 2727-2739. DOI: 10.1111/mec.12771.

546 Crump, A., \& Omura, S. 2011. Ivermectin, 'wonder drug' from Japan: the human use perspective. Proceedings of the Japan Academy, Series B, 87(2):13-28. DOI: 10.2183/pjab.87.13.

Delpuech, J.M., Frey, F., \& Carton, Y. 1996. Action of insecticides on the cellular immune reaction of Drosophila melanogaster against the parasitoid Leptopilina boulardi. Environmental Toxicology and Chemistry: An International Journal, 15(12):2267-2271. DOI:

552 10.1002/etc.5620151221.

553 DeSilva, D., Hemingway, J., Ranson, H., \& Vaughan, A. 1997. Resistance to insecticides in 554 insect vectors of disease: est $\alpha 3$, a novel amplified esterase associated with amplified est $\beta 1$ from 
555 insecticide resistant strains of the mosquito Culex quinquesfasciatus. Experimental

556 parasitology, 87(3):253-259. DOI: 10.1006/expr.1997.4245.

557 Dreyer, S.M., Morin, K.J., \& Vaughan, J.A. 2018. Differential susceptibilities of Anopheles

558 albimanus and Anopheles stephensi mosquitoes to ivermectin. Malaria journal, 17(1):148.

559 DOI: 10.1186/s12936-018-2296-3.

560 Drinyaev, V.A., Kruglyak, E.B., Mosin, V.A., Ter-Simonyan, V.G., Novik, T.S., Rusakov, S.V.,

561 Berezina, N.S., Berezkina, N.E., Sterlina, T.S. 1999. Physicochemical and biological properties

562 of aversectin C. Appl. Biochem. Microbiol, 35(2):177-182.

563 Dubovskiy, I. M., Kryukova, N. A., Glupov, V. V., \& Ratcliffe, N. A. 2016. Encapsulation and

564 nodulation in insects. Invertebrate Survival Journal, 13(1), 229-246.

565 Dubovskiy, I.M., Slyamova, N.D., Kryukov, V.Y., Yaroslavtseva, O.N., Levchenko, M.V.,

566 Belgibaeva, A.B., ... \& Glupov, V.V. 2012. The activity of nonspecific esterases and glutathione-

567 S-transferase in Locusta migratoria larvae infected with the fungus Metarhizium anisopliae

568 (Ascomycota, Hypocreales). Entomological review, 92(1):27-31. DOI:

569 10.1134/S0013873812010022.

570 Dubovskiy, I.M., Whitten, M.M.A., Yaroslavtseva, O.N., Greig, C., Kryukov, V.Y., Grizanova, 571 E.V., Mukherjee, K., Vilcinskas, A., Glupov, V.V., Butt, T.M. 2013. Can insects develop

572 resistance to insect pathogenic fungi? PLoS One, 8(4):e60248. DOI:

573 10.1371/journal.pone.0060248.

574 Freitas, R.M.C.D., Faria, M.D.A., Alves, S.N., \& Melo, A.L.D. 1996. Effects of ivermectin on

575 Culex quinquefasciatus larvae. Revista do Instituto de Medicina Tropical de São

576 Paulo, 38(4):293-298. DOI:10.1590/S0036-46651996000400010.

577 Furlong, M.J., \& Groden, E. 2003. Starvation induced stress and the susceptibility of the

578 Colorado potato beetle, Leptinotarsa decemlineata, to infection by Beauveria bassiana. Journal

579 of Invertebrate Pathology, 83(2):127-138. DOI: 10.1016/S0022-2011(03)00066-1.

580 Gaidyshev, I.P. 2004. Solution of scientific and engineering tasks by means of Excel, VBA and 581 C/C++. St. Petersburg: BKhV-Petersburg.

582 Gandhe, A.S., Janardhan, G., \& Nagaraju, J. 2007. Immune upregulation of novel antibacterial

583 proteins from silkmoths (Lepidoptera) that resemble lysozymes but lack muramidase activity.

584 Insect biochemistry and molecular biology, 37(7):655-666. DOI: 10.1016/j.ibmb.2007.03.013.

585 Garrido-Jurado, I., Alkhaibari, A., Williams, S.R., Oatley-Radcliffe, D.L., Quesada-Moraga, E.,

$586 \&$ Butt, T.M. 2016. Toxicity testing of Metarhizium conidia and toxins against aquatic

587 invertebrates. Journal of pest science, 89(2):557-564. DOI: 10.1007/s10340-015-0700-0.

588 Gorman, M.J., An, C., \& Kanost, M.R. 2007. Characterization of tyrosine hydroxylase from

589 Manduca sexta. Insect biochemistry and molecular biology, 37(12):1327-1337. DOI:

590 10.1016/j.ibmb.2007.08.006.

591 Greenfield, B.P., Peace, A., Evans, H., Dudley, E., Ansari, M.A., \& Butt, T.M. 2015.

592 Identification of Metarhizium strains highly efficacious against Aedes, Anopheles and Culex

593 larvae. Biocontrol science and technology, 25(5):487-502. DOI:

$59410.1080 / 09583157.2014 .989813$.

595 Gruntenko, N.E., Karpova, E.K., Adonyeva, N.V., Chentsova, N.A., Faddeeva, N.V., Alekseev,

596 A.A., \& auschenbach, I.Y. 2005. Juvenile hormone, 20-hydroxyecdysone and dopamine

597 interaction in Drosophila virilis reproduction under normal and nutritional stress

598 conditions. Journal of insect physiology, 51(4):417-425.

599 Hammer, O., Harper, D.A., \& Ryan, P.D. 2001. Palaeontological statistics software package for

600 education and data analysis. Palaeontologia Electronica, 4(1):1-9. 
601 Huxham, I. M., Lackie, A. M., \& McCorkindale, N. J. 1989. Inhibitory effects of

602 cyclodepsipeptides, destruxins, from the fungus Metarhizium anisopliae, on cellular immunity in

603

604 insects. Journal of Insect Physiology, 35(2), 97-105. DOI: 10.1016/0022-1910(89)90042-5.

605 Habig, W.H., Pabst, M.J., \& Jakoby, W.B. 1974. Glutathione S-transferases. The first enzymatic step in mercapturic acid formation. Journal of biological Chemistry, 249(22), 7130-7139.

606 Hirashima, A., Sukhanova, M. J., \& Rauschenbach, I. Y. 2000. Biogenic amines in Drosophila

607 virilis under stress conditions. Bioscience, biotechnology, and biochemistry, 64(12):2625-2630.

608 DOI: $10.1271 / \mathrm{bbb} .64 .2625$.

609 Jozefiak, A., \& Engberg, R.M. 2017. Insect proteins as a potential source of antimicrobial

610 peptides in livestock production. A review. Journal of Animal and Feed Sciences, 26(2):87-99.

611 DOI:10.22358/jafs/69998/2017.

612 Kokoz, Y.M., Tsyganova, V.G., Korystova, A.F., Grichenko, A.S., Zenchenko, K.I., Drinyaev,

613 V.A., ... \& Victorov, A.V. 1999. Selective cytostatic and neurotoxic effects of avermectins and

614 activation of the GABA $\alpha$ receptors. Bioscience reports, 19(6):535-546. DOI:

615 10.1023/A:1020262811459.

616 Korystov, Y. N., Mosin, V. A., Shaposhnikova, V. V., Levitman, M. K., Kudryavtsev, A. A.,

617 Kruglyak, E. B., ... \& Drinyaev, V. A. 1999. A comparative study of the effects of aversectin C,

618 abamectin and ivermectin on apoptosis of rat thymocytes induced by radiation and

619 dexamethasone. Acta Veterinaria Brno, 68(1), 23-29. DOI:10.2754/avb199968010023.

620 Li, X., Schuler, M. A., \& Berenbaum, M. R. 2007. Molecular mechanisms of metabolic

621 resistance to synthetic and natural xenobiotics. Annu. Rev. Entomol., 52, 231-253. DOI:

622 10.1146/annurev.ento.51.110104.151104.

623 Ling, E., \& Yu, X.Q. 2005. Prophenoloxidase binds to the surface of hemocytes and is involved

624 in hemocyte melanization in Manduca sexta. Insect biochemistry and molecular

625 biology, 35(12):1356-1366. DOI: 10.1016/j.ibmb.2005.08.007.

626 Loutelier, C., Cherton, J. C., \& Lange, C. 1994. Conjugation reactions of cyclodepsipeptide to

627

628

629 glutathionyl adducts by direct 'in-beam'synthesis under negative-ion fast-atom bombardment conditions. Rapid Communications in Mass Spectrometry, 8(10), 844-848. DOI: 10.1002/rcm.1290081010.

630 Maioli, M.A., de Medeiros, H.C., Guelfi, M., Trinca, V., Pereira, F.T., \& Mingatto, F.E. 2013.

631 The role of mitochondria and biotransformation in abamectin-induced cytotoxicity in isolated rat 632 hepatocytes. Toxicology in Vitro, 27(2):570-579. DOI: 10.1016/j.tiv.2012.10.017.

633 Mohrig, W., \& Messner, B. 1968. Lysozyme as antibacterial agent in honey and bees

634 venom. Acta biologica et medica Germanica, 21(1):85.

635 Ortiz-Urquiza, A., Luo, Z., \& Keyhani, N.O. 2015. Improving mycoinsecticides for insect 636 biological control. Applied microbiology and biotechnology, 99(3):1057-1068. DOI:

637 10.1007/s00253-014-6270-x.

638 Pal, S., Leger, R. J. S., \& Wu, L. P. 2007. Fungal peptide Destruxin A plays a specific role in 639 suppressing the innate immune response in Drosophila melanogaster. Journal of Biological 640 Chemistry, 282(12), 8969-8977. DOI: 10.1074/jbc.M605927200.

641 Paris, M., Tetreau, G., Laurent, F., Lelu, M., Despres, L., David, J.P. 2011. Persistence of 642 Bacillus thuringiensis israelensis (Bti) in the environment induces resistance to multiple Bti 643 toxins in mosquitoes. Pest Management Science. 67(1):122-8. DOI:

644 10.1002/ps.2046PMID:21162152.

645 Polenogova, O.V., Kabilov, M.R., Tyurin, M.V., Rotskaya, U.N., Krivopalov, A.V., Morozova, 646 V.V., ... \& Glupov, V.V. 2019. Parasitoid envenomation alters the Galleria mellonella midgut 
647 microbiota and immunity, thereby promoting fungal infection. Scientific reports, 9(1):4012.

648 DOI: 10.1038/s41598-019-40301-6.

649 Prabhakaran, S.K., \& Kamble, S.T. 1995. Purification and characterization of an esterase

650 isozyme from insecticide resistant and susceptible strains of German cockroach, Blattella

651 germanica (L.). Insect biochemistry and molecular biology, 25(4):519-524. DOI: 10.1016/0965-

$652 \quad 1748(94) 00093-\mathrm{E}$.

653 Ramirez, J.L., Muturi, E.J., Dunlap, C., \& Rooney, A.P. 2018. Strain-specific pathogenicity and 654 subversion of phenoloxidase activity in the mosquito Aedes aegypti by members of the fungal

655 entomopathogenic genus Isaria. Scientific reports, 8(1):9896. DOI: 10.1038/s41598-018-28210-

6566.

657 Ranson, H., \& Lissenden, N. 2016. Insecticide resistance in African Anopheles mosquitoes: a

658 worsening situation that needs urgent action to maintain malaria control. Trends in

659 parasitology, 32(3), 187-196. DOI: 10.1016/j.pt.2015.11.010.

660 Robertson, J.L., \& Preisler, H.K. Pesticide bioassays with arthropods. 1992. CRC Boca Raton,

661 FL. DOI: 10.1201/9781315373775.

662 Scheirer, C.J., Ray, W.S., \& Hare, N. 1976. The analysis of ranked data derived from completely 663 randomized factorial designs. Biometrics, 32(2):429-434. DOI: 10.2307/2529511.

664 Scholte, E.J., Njiru, B.N., Smallegange, R.C., Takken, W., \& Knols, B.G. 2003. Infection of

665 malaria (Anopheles gambiae ss) and filariasis (Culex quinquefasciatus) vectors with the

666 entomopathogenic fungus Metarhizium anisopliae. Malaria journal, 2(1):29. DOI:

667 10.1186/1475-2875-2-29.

668 Sivakumar, G., Rangeshwaran, R., Yandigeri, M.S., Mohan, M., Venkatesan, T., Ballal, C.R., ... $669 \&$ Verghese, A. 2017. Characterization and role of gut bacterium Bacillus pumilus on nutrition

670 and defense of leafhopper (Amrasca biguttula biguttula) of cotton. INDIAN J. Agr. Sci, 87:534-

671539.

672 Sivkov G.S., Yakovlev V.V., Chashov I.A. 1998. Influence of the animal's immune response

673 indicatirs. Veterinarnaya Medicina, 5:29-31. (in Russian).

674 Sherratt, P. J., \& Hayes, J. D. 2002. Glutathione S-transferases. Enzyme systems that metabolise

675 drugs and other xenobiotics, 319-352.

676 Shoukat, R.F., Freed, S., Ahmad, K.W., \& Rehman, A.U. 2018. Assessment of Binary Mixtures

677 of Entomopathogenic Fungi and Chemical Insecticides on Biological Parameters of Culex

678 pipiens (Diptera: Culicidae) under Laboratory and Field Conditions. Pakistan Journal of

679 Zoology, 50(1):299-299. DOI: 10.17582/journal.pjz/2018.50.1.299.309.

680 Smith, L. B., Kasai, S., \& Scott, J. G. 2016. Pyrethroid resistance in Aedes aegypti and Aedes

681 albopictus: Important mosquito vectors of human diseases. Pesticide biochemistry and

682 physiology, 133, 1-12. DOI: 10.1016/j.pestbp.2016.03.005.

683 Su, T., Thieme, J., Ocegueda, C., Ball, M., \& Cheng, M.L. 2017. Resistance to Lysinibacillus

684 sphaericus and other commonly used pesticides in Culex pipiens (Diptera: Culicidae) from

685 Chico, California. Journal of medical entomology, 55(2):423-428. DOI: 10.1093/jme/tjx235.

686 Tilquin, M., Paris, M., Reynaud, S., Despres, L., Ravanel, P., Geremia, R.A., \& Gury, J. 2008.

687 Long lasting persistence of Bacillus thuringiensis subsp. israelensis (Bti) in mosquito natural

688 habitats. PLoS One, 3(10):e3432. DOI: 10.1371/journal.pone.0003432.

689 Tang, G., Xiong, Y., Liu, Y., Song, Z., Yang, Y., Shen, G., ... \& Jiang, H. 2019. The

690 transcription factor MafB regulates the susceptibility of Bactrocera dorsalis to avermectin via

691 GSTz2. Frontiers in Physiology, 10, 1068. DOI: 10.3389/fphys.2019.01068. 
692 Tokura, A., Fu, G. S., Sakamoto, M., Endo, H., Tanaka, S., Kikuta, S., ... \& Sato, R. 2014.

693 Factors functioning in nodule melanization of insects and their mechanisms of accumulation in 694 nodules. Journal of insect physiology, 60, 40-49. DOI: 10.1016/j.jinsphys.2013.11.003.

695 Tolle, M.A. 2009. Mosquito-borne diseases. Current problems in pediatric and adolescent health

696 care, 39(4):97-140. DOI: 10.1016/j.cppeds.2009.01.001.

697 Tomilova, O.G., Kryukov, V.Y., Duisembekov, B.A., Yaroslavtseva, O.N., Tyurin, M.V.,

698 Kryukova, N.A., ... \& Glupov, V.V. 2016. Immune-physiological aspects of synergy between

699 avermectins and the entomopathogenic fungus Metarhizium robertsii in Colorado potato beetle

700 larvae. Journal of invertebrate pathology, 140:8-15. DOI: 10.1016/j.jip.2016.08.008.

701 Tomilova, O.G., Yaroslavtseva, O.N., Ganina, M.D., Tyurin, M.V., Chernyak, E.I., Senderskiy,

702 I.V., ... \& Glupov, V.V. 2019. Changes in antifungal defence systems during the intermoult

703 period in the Colorado potato beetle. Journal of insect physiology, 116:106-117. DOI:

704 10.1016/j.jinsphys.2019.05.003.

705 Tounou, A.K., Kooyman, C., Douro-Kpindou, O.K., \& Poehling, H.M. 2008. Interaction

706 between Paranosema locustae and Metarhizium anisopliae var. acridum, two pathogens of the

707 desert locust, Schistocerca gregaria under laboratory conditions. Journal of invertebrate

708 pathology, 97(3):203-210. DOI: 10.1016/j.jip.2007.10.002.

709 Vivekanandhan, P., Karthi, S., Shivakumar, M.S., \& Benelli, G. 2018. Synergistic effect of

710 entomopathogenic fungus Fusarium oxysporum extract in combination with temephos against

711 three major mosquito vectors. Pathogens and global health, 112(1):37-46. DOI:

$71210.1080 / 20477724.2018 .1438228$.

713 Vontas, J., Ranson, H., \& Alphey, L. 2010. Transcriptomics and disease vector control. BMC

714 biology, 8(1):52. DOI: 10.1186/1741-7007-8-52.

715 Wang, B., Kang, Q., Lu, Y., Bai, L., \& Wang, C. 2012. Unveiling the biosynthetic puzzle of

716 destruxins in Metarhizium species. Proceedings of the National Academy of Sciences, 109(4),

717 1287-1292. DOI: 10.1073/pnas.1115983109.

718 Wei, G., Lai, Y., Wang, G., Chen, H., Li, F., \& Wang, S. 2017. Insect pathogenic fungus

719 interacts with the gut microbiota to accelerate mosquito mortality. Proceedings of the National

720 Academy of Sciences, 114(23):5994-5999. DOI: 10.1073/pnas.1703546114.

721 Wu, S.F., Xu, G., Stanley, D.,Huang, J., \& Ye, G.Y. 2015. Dopamine modulates hemocyte

722 phagocytosis via a D1-like receptor in the rice stem borer, Chilo suppressalis. Scientific

723 reports, 5:12247. DOI: 10.1038/srep12247.

724 Yaroslavtseva, O.N., Dubovskiy, I.M., Khodyrev, V.P., Duisembekov, B.A., Kryukov, V.Y., \&

725 Glupov, V.V. 2017. Immunological mechanisms of synergy between fungus Metarhizium

726 robertsii and bacteria Bacillus thuringiensis ssp. morrisoni on Colorado potato beetle

727 larvae. Journal of insect physiology, 96:14-20. DOI: 10.1016/j.jinsphys.2016.10.004.

728 Yassine, H., Kamareddine, L., \& Osta, M.A. 2012. The mosquito melanization response is

729 implicated in defense against the entomopathogenic fungus Beauveria bassiana. PLoS

730 pathogens, 8(11):e1003029. DOI: 10.1371/journal.ppat.1003029.

731 Zachary, D., \& Hoffmann, D. 1984. Lysozyme is stored in the granules of certain haemocyte

732 types in Locusta. Journal of insect physiology, 30(5):405-411. DOI: 10.1016/0022-

733 1910(84)90098-2.

734 Zhang, F., Sun, X.X., Zhang, X.C., Zhang, S., Lu, J., Xia, Y.M., ... \& Wang, X.J. 2018. The

735 interactions between gut microbiota and entomopathogenic fungi: a potential approach for

736 biological control of Blattella germanica (L.). Pest management science, 74(2), 438-447. DOI:

$737 \quad 10.1002 /$ ps.47262018. 
Figure 1

Mortality dynamics of $A$ e. aegypti larvae after treatment with M. robertsii $\left(1 \times 10^{6}\right.$ conidia/ml), avermectins $(0.00001 \%)$ and their combination.

The control was treated with distilled water. The asterisks $(*)$ indicate a synergistic effect $\left(\chi^{2}\right.$ $>18.5, \mathrm{df}=1, \mathrm{P}<0.001$, see Table S1).

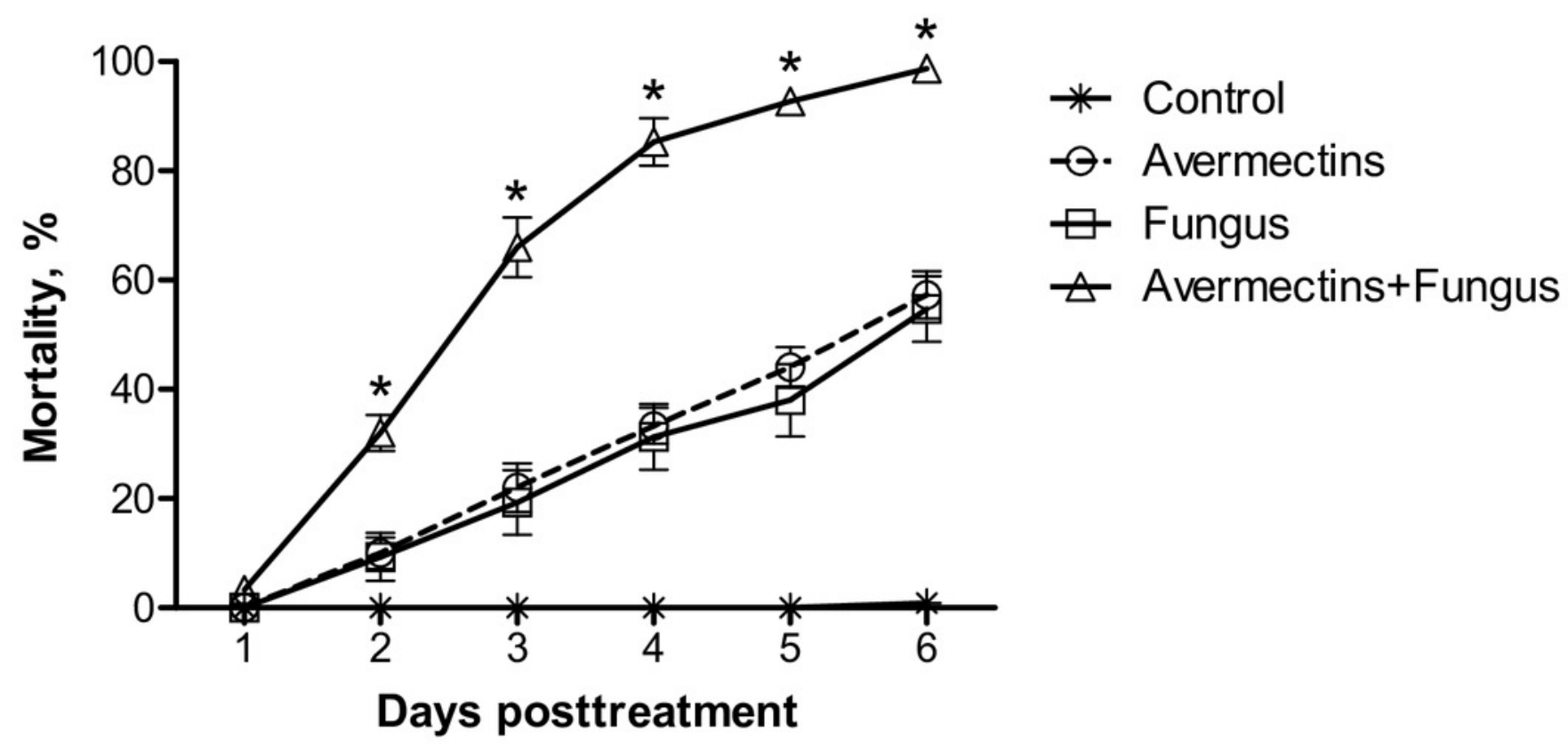


Figure 2

The colonization of $A$. aegypti by Metarhizium.

(A) Accumulation of conidia in the gut and colonization of the hemocoel by hyphal bodies. (B) Colonization of the fat body. (C-E) Mosquito larvae with surface conidiation of Metarhizium in a moist chamber. (F) Nongerminated conidia in a sample of water in which infected larvae were maintained. Scale bar: $20 \mu \mathrm{m}$. 

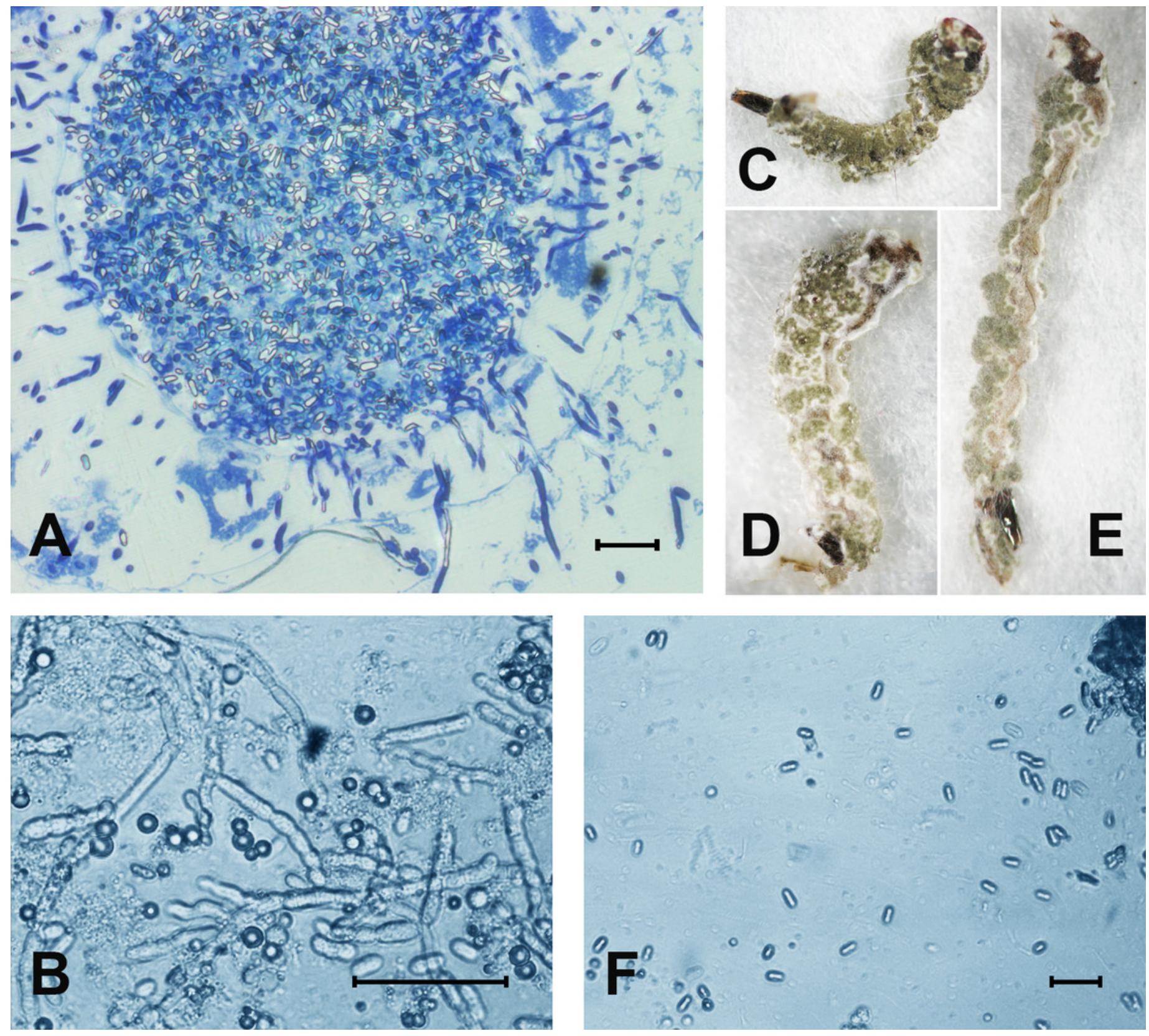
Figure 3

Activity of PO in the whole-body homogenates of Ae. aegypti larvae after treatment with $M$. robertsii, avermectins and their combination.

In the control treatment, equal amounts of water were added. Error bars represent the standard error of the mean. Significant differences are indicated with different letters within one time point (Dunn's test, $\mathrm{P}<0.05$ ).

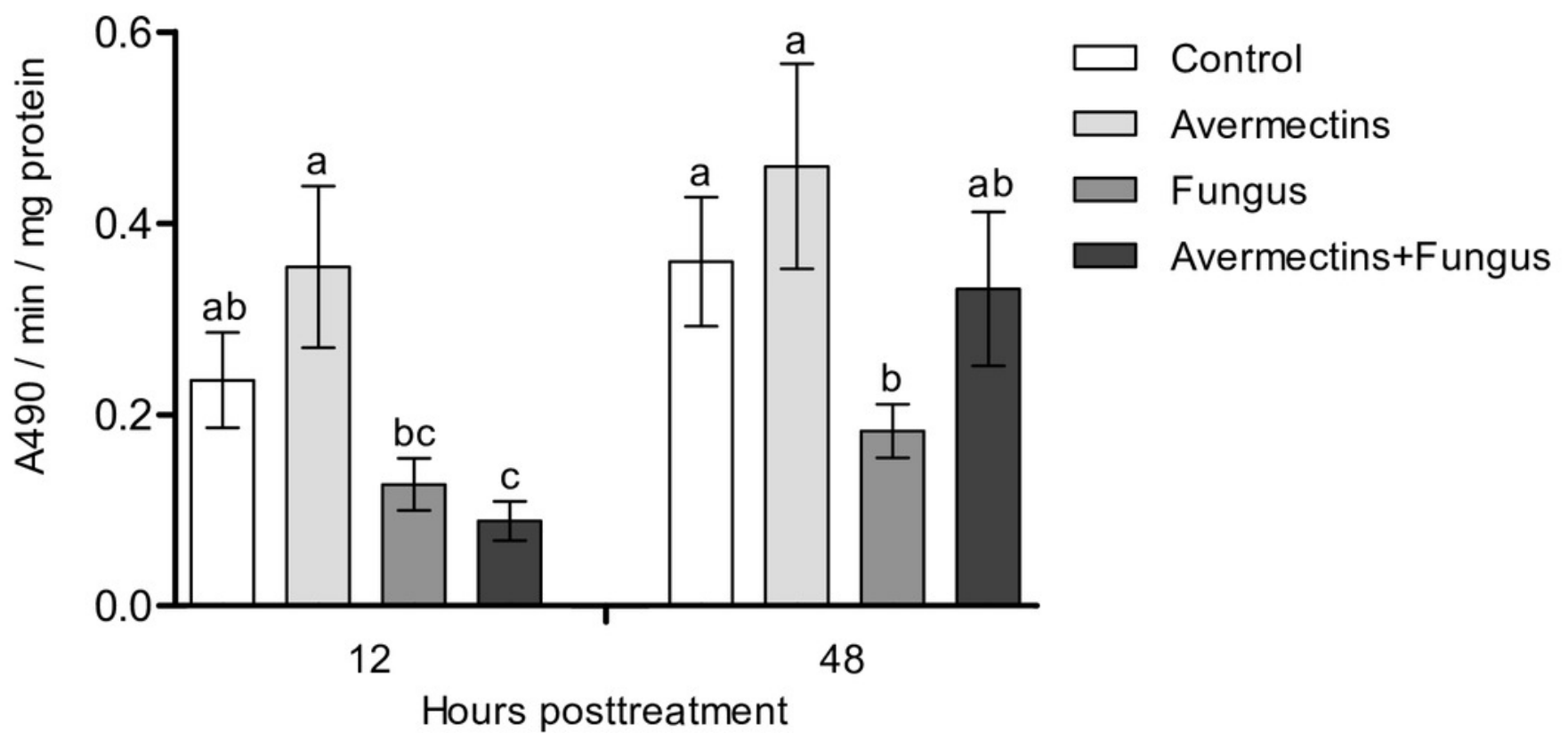


Figure 4

Dopamine concentration in whole-body homogenates of Ae. aegypti larvae after treatment with $M$. robertsii, avermectins and their combination.

In the control treatment, equal amounts of water were added. Error bars represent the standard error of the mean. Significant differences are indicated by different letters within one time point (HSD Tukey test, $\mathrm{P}<0.05$ ).

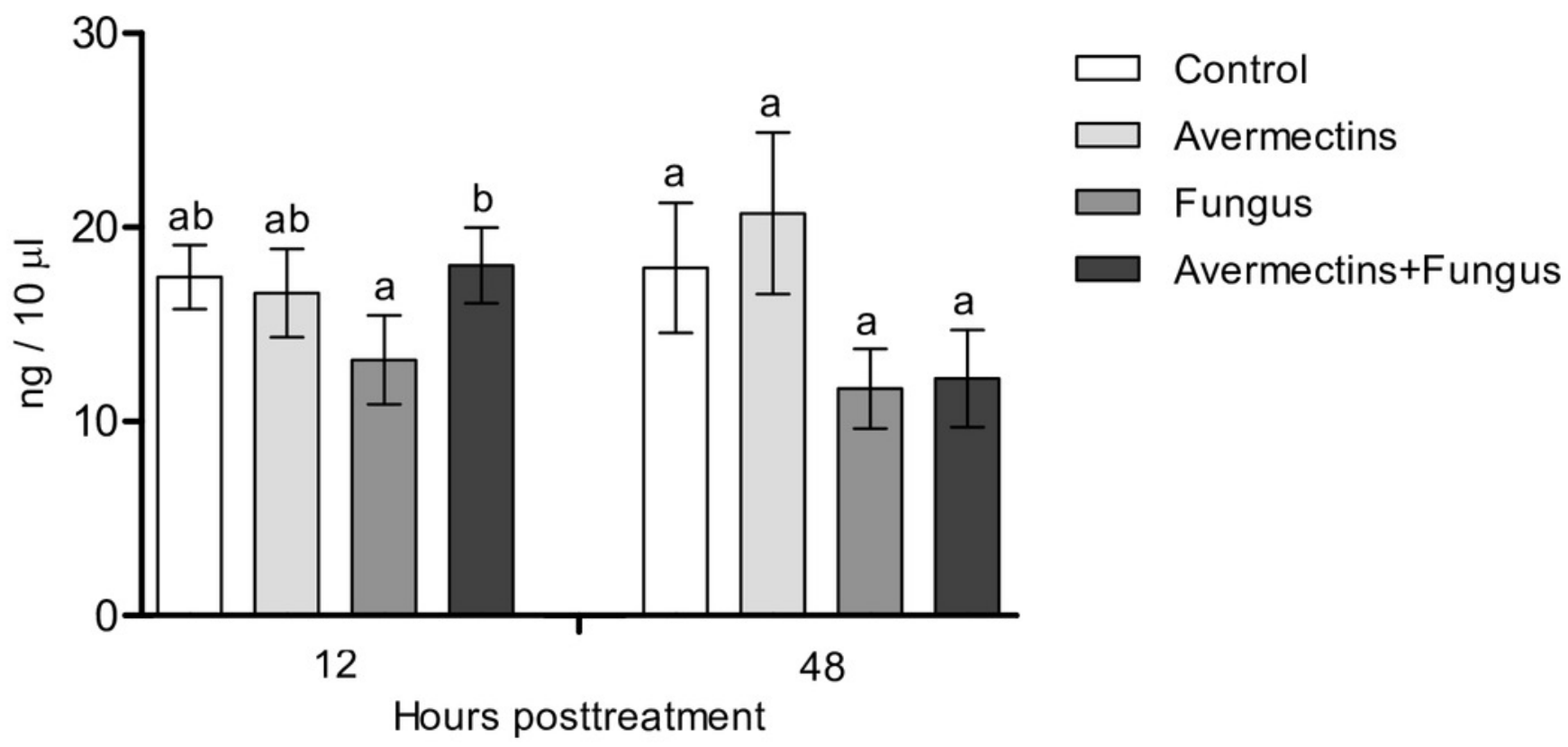


Figure 5

GST (A) and EST (B) activity in whole-body homogenates of Ae. aegypti larvae after treatment with $M$. robertsii, avermectins and their combination.

In the control treatment, equal amounts of water were added. Error bars represent the standard error of the mean. Significant differences are indicated by different letters within one time point (Dunn's test, $\mathrm{P}<0.05$ ). 


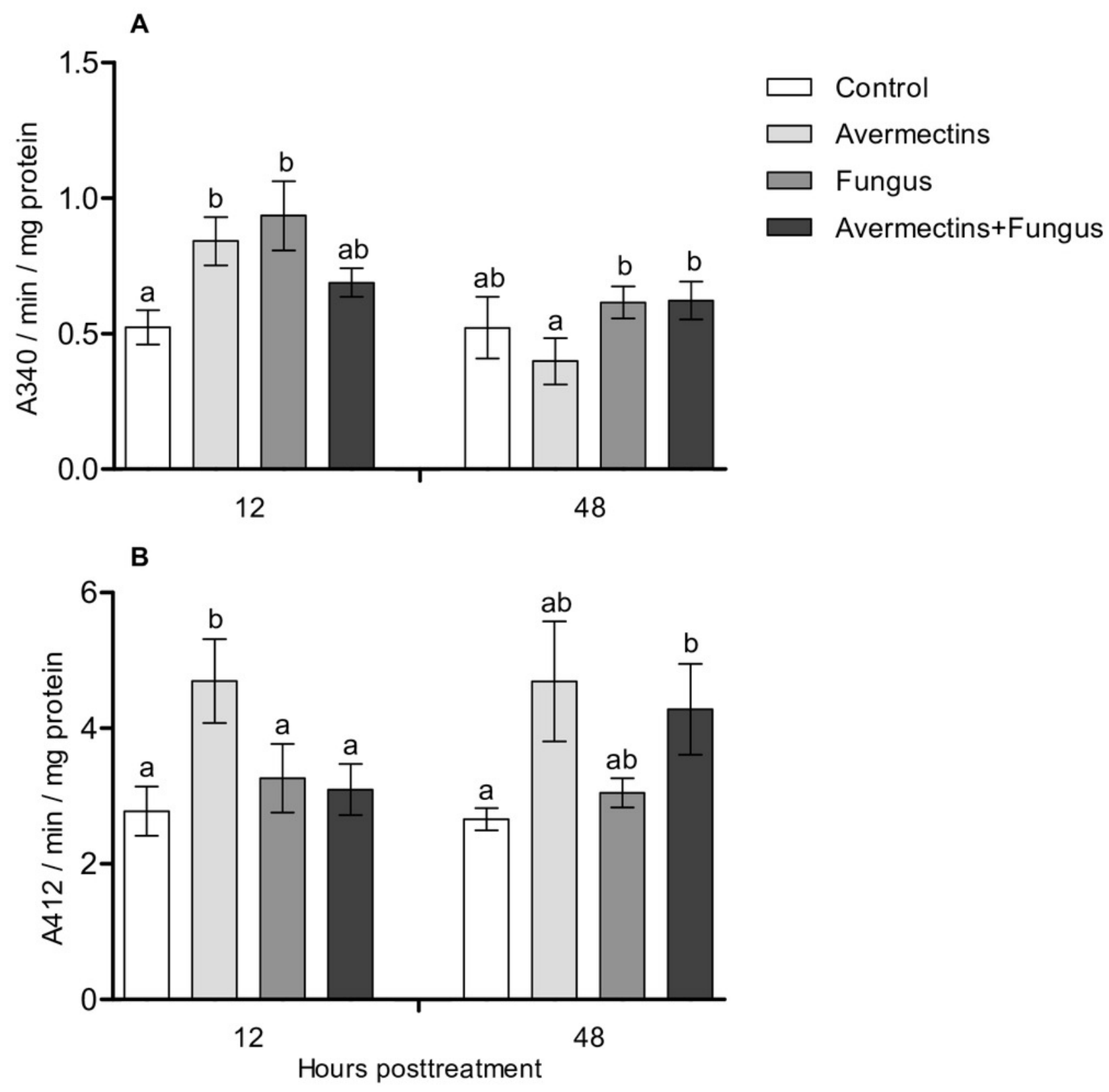




\section{Figure 6}

Acid protease activity in whole-body homogenates of Ae. aegypti larvae after treatment with $M$. robertsii, avermectins and their combination.

In the control treatment, equal amounts of water were added. Error bars represent the standard error of the mean. Significant differences are indicated by different letters within one time point (Dunn's test, $\mathrm{P}<0.05$ ).

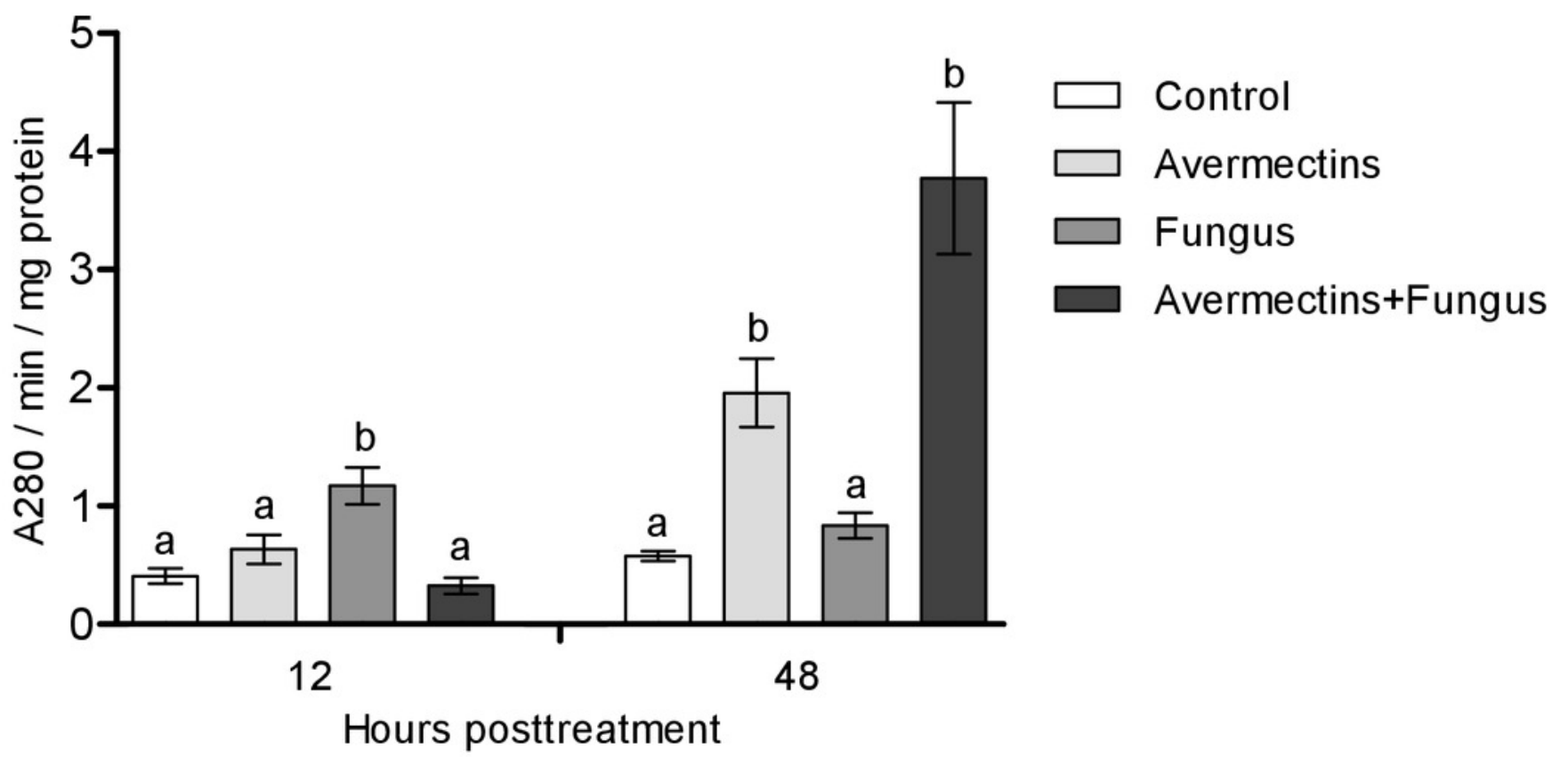




\section{Figure 7}

Lysozyme-like activity in whole-body homogenates of Ae. aegypti larvae after treatment with $M$. robertsii, avermectins and their combination.

In the control treatment, equal amounts of water were added. Error bars represent the standard error of the mean. Significant differences are indicated by different letters within one time point (Dunn's test, $\mathrm{P}<0.05$ ).

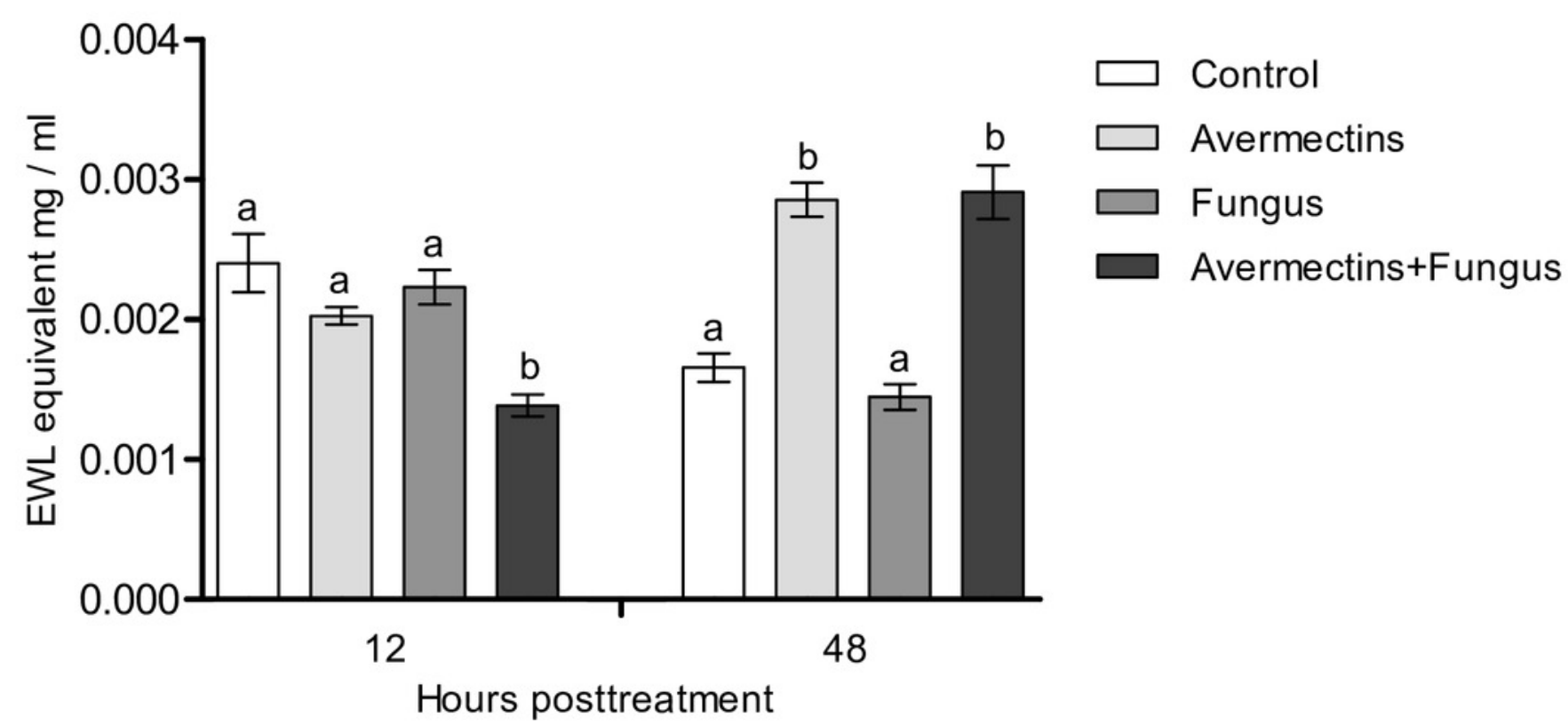




\section{Figure 8}

Colony forming units of $M$. robertsii (A) and cultivable bacteria (B) in whole-body homogenates of Ae. aegypti larvae after treatment with $M$. robertsii, avermectins and their combination.

Error bars show min and max values. Significant differences are indicated by different letters (Dunn's test, $\mathrm{P}<0.05$ ).

A

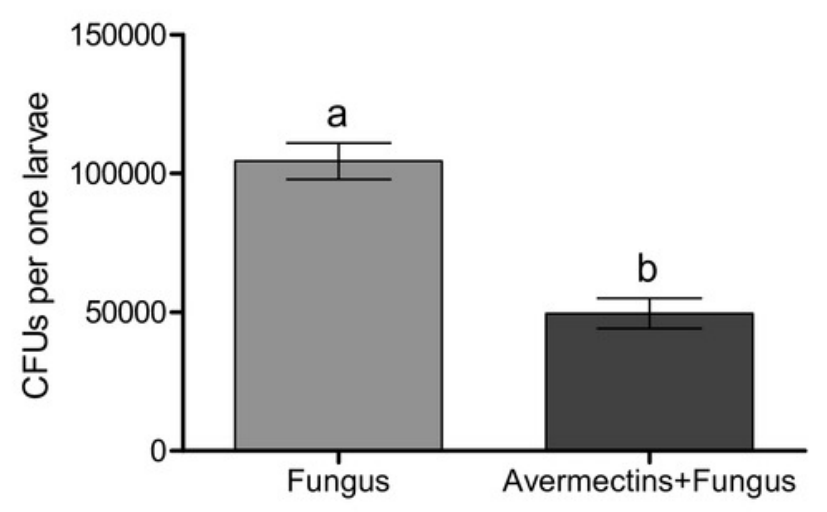

B

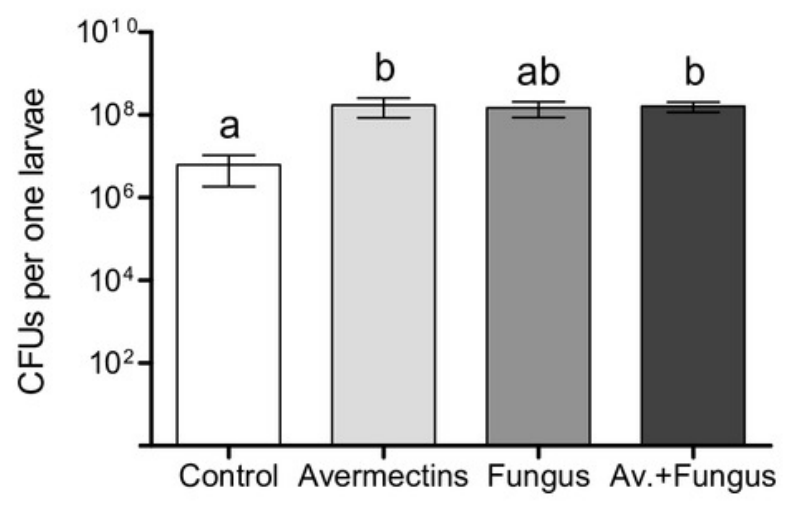

